\title{
Can We All Get Along? \\ Incentive Contracts to Bridge the Marketing and Operations Divide
}

\author{
Kinshuk Jerath* \\ Serguei Netessine \\ Z. John Zhang \\ The Wharton School \\ University of Pennsylvania \\ Jon M. Huntsman Hall \\ 3730 Walnut Street \\ Philadelphia, PA 19104-6340
}

June 2007

${ }^{*}$ Kinshuk Jerath is a doctoral candidate at the Wharton School of the University of Pennsylvania. Serguei Netessine is Associate Professor of Operations Management at the Wharton School of the University of Pennsylvania. Z. John Zhang is Professor of Marketing at the Wharton School of the University of Pennsylvania. E-mail correspondence: kinshuk@wharton.upenn.edu. 


\title{
Can We All Get Along? \\ Incentive Contracts to Bridge the Marketing and Operations Divide
}

\begin{abstract}
The marketing and operations management arms in a firm must work in coordination marketing efforts to create demand go to waste if supply is suboptimal, and vice versa. However, achieving this coordination has remained a long-standing problem, because in most firms these units are managed in a decentralized manner. A major source of conflict is that marketing compensation is usually heavily weighted towards sales whereas operations compensation is usually heavily weighted towards expense reduction. In this paper, we invoke agency theory to determine compensation plans for sales and operations managers to coordinate their activities in the best interests of the firm.

We first show in a single product scenario that, by rewarding the sales manager for increasing sales and the operations manager for reducing total cost, a firm cannot coordinate the two functions. Furthermore, a simple profit-sharing contract does not work, either, because of the free-rider problem. However, we show that each of the following two contract schemes can always achieve coordination: (1) rewarding the operations manager separately for increasing sales and reducing costs, and (2) rewarding him separately for reducing missed sales and leftover supply. We thus show that choosing the right performance metrics (before choosing the contract parameters) can mean the difference between being able to align the interests of the salesforce with those of the firm and not being able to do so. We characterize how the parameters of the optimal contracts vary with product and demand characteristics. For instance, we find that when costs are high, the sales commission for the sales manager can increase with uncertainty in demand, a result which runs contrary to results from classic agency theory.

In a multiproduct scenario, when one manager manages several products, the coordinating contracts are fairly complicated. However, we show that simple contracts, which we characterize as either a sales-focused organization (a separate sales manager for every product, one operations manager for all products) or an operations-focused organization (a separate operations manager for every product, one sales manager for all products), can help a firm to achieve near perfect coordination. This is in line with the observation that most firms have either a "sales image" or a "cost image," and sheds some light on how the underlying objective of aligning marketing and operations, while keeping the size of the salesforce small and compensation contracts simple, can influence the organization of a firm.
\end{abstract}

Keywords: marketing-operations interface, salesforce compensation, agency theory. 


\section{Introduction}

The aim of marketing is to create demand, and the aim of operations management ${ }^{1}$ is to match supply with demand. Clearly, for every firm, these two functions are closely connected - actual sales increase with higher demand only if supply is also up to the mark - and researchers and practitioners widely agree that harmony between these two arms of the firm will improve profits (Hausman, Montgomery and Roth 2002). Several examples to support this view can be furnished from the industry. For instance, Delaney-Klinger, Boyer and Frohlich (2003) conduct a comparative analysis of online grocers and show how the now defunct online grocer Webvan "provides an excellent example of the results of a misalignment between marketing and operations strategies" while companies with better alignment between these strategies like Tesco in the UK and Albertson's in the USA have profitable Internet channels for selling groceries. Fisher, Maltz and Jaworski (1997) attribute the failure of Texas Instruments' desktop computer business and Canon's success in the mini-copier business to the failure and success, respectively, of inter-functional coordination.

Synchronizing these two functions, however, is easier said than done - marketing personnel claim that logistics personnel are "often willing to forsake the customer to save on costs" while logistics personnel are "frustrated by the relative indifference towards the logistics function of their marketing colleagues" (Ellinger, Keller and Hansen 2006). This discord has remained a classic issue for researchers working on the marketing-operations management interface, leading to the well-known article in Harvard Business Review titled "Can marketing and manufacturing coexist?" (Shapiro 1977) and to special issues of leading journals like Management Science devoted to attempts at solving the problem (Ho and Tang 2004). Shapiro (1977) lays out some broad areas of "necessary cooperation but potential conflict," which include capacity planning for uncertain sales, quality assurance, breadth of product line, the introduction of new products, and coordinating supply decisions with marketing decisions. The various attempts to bridge this gap usually focus on a specific source of discord and a solution to it. We will review the relevant literature in this area later. In this paper, we will focus on the last issue pointed out above, i.e., coordinating demand-enhancing efforts on the marketing side and product availablity on the operations side.

The following simple scenario will illustrate the case in point. A firm selling a single product with random demand employs a marketing manager (representing the sales arm of the firm) whose job is to increase the level of demand by exerting sales effort and an operations manager (representing the operations arm of the firm) whose job is to match supply with demand. ${ }^{2}$ Most firms manage their operations arms as cost centers, separately from the sales arms, which are managed as revenue centers (Harps 2002). Such a setup with random demand is subject to the discord between marketing and logistics discussed above - the marketing manager complains that her effort is going to waste because of too little being supplied so that she loses on sales, while the logistics manager

\footnotetext{
${ }^{1}$ We use "operations management" and "logistics" interchangeably.

${ }^{2}$ In general, the job of the operations manager is to make the product available when demand is realized. This encompasses various scenarios like deciding the quantity of the product to be produced in a manufacturing setting, deciding the quantity to be ordered and stocked as inventory in a retail setting, etc. For simplicity, we will refer to his job as "supplying inventory" all through the paper.
} 
complains that the marketing manager wants too much to be supplied which will increase costs, while demand might not turn out to be that high. The misalignment occurs because of the problem in the incentive structure of the managers. Shapiro (1977) identifies this as the prime reason for the gap and states:

"On the one hand, the marketing people are judged on the basis of profitable growth of the company in terms of sales. ... Unfortunately, the marketers are sometimes more sales-oriented than profit-oriented. On the other hand, the manufacturing people are often evaluated on running a smooth operation at minimum cost. Similarly unfortunately, they are sometimes more cost-oriented than profit-oriented. ... Because the marketers and manufacturers both want to be evaluated positively and rewarded well, each function responds as the system asks it to in order to protect its self-interest."

Recent evidence from the Internet forum RetailWire points out that this problem of clashing compensation plans is a doggedly persistent problem thirty years later (RetailWire 2007). Ellinger et al. (2006) and Narayanan and Raman (2004) provide several other examples of coordination failures between marketing and operations due to misaligned incentives, most notably that of Cisco, when in 2001 its much-vaunted supply chain snapped, leading to an estimated loss of $\$ 2.5$ billion and a $6 \%$ fall in share price on the day of the announcement. However, there is evidence that several firms tie the performance evaluation of their operations units to service measures like sales achieved and fill rate, ${ }^{3}$ rather than tying the compensation directly to costs (Cohen, Agrawal and Agrawal 2006).

In this paper, we explore whether incentive contracts can be written so that both sales and operations managers, while individually maximizing their utilities based on the trade-off between compensation provided and effort exerted, make their respective choices in such a way that the best interests of the firm are served. We find that the answer to this question is in the affirmative, and has several interesting aspects to it. Broadly speaking, the firm can write simple contracts to coordinate marketing and logistics, but needs to carefully choose not just the contract parameters, but also the performance metrics that should be contracted upon. We find that if the marketing manager is compensated based on sales and the operations manager is compensated based on total cost (which is the norm in most firms, as discussed above), then a typical firm will not be able to coordinate their actions. Under random demand, increasing supply increases marginal cost and expected cost from unsold goods, and reduces the expected cost from missed sales. Since the first two components of cost typically dominate the third, the operations manager does not have sufficient incentives to supply the optimal quantity. Further, a simple profit-sharing contract does not work, either, because of the free-rider problem.

We show that the firm can incentivize the operations manager to supply the optimal quantity by extending his contract in one of two ways: (1) by penalizing him on total cost but rewarding

\footnotetext{
${ }^{3}$ defined as $1-\frac{\text { backorders }}{\text { mean demand }}$
} 
him for sales (which we call an interdependent contract because the operations manager is being compensated in part based on metrics borrowed from the sales arm of the firm), and (2) by compensating him separately on the different components of the inventory cost, i.e., penalizing him separately on unsold inventory and backorders (which we call an information-based contract because implementing the contract requires the firm to use detailed cost information). The simplest interdependent contract involves compensating the operations manager only on sales (with the total cost muted out of the contract specification), and the simplest information-based contract involves compensating the operations manager only on backorders (with the other components of inventory cost muted out of the contract specification). Both these schemes can always achieve coordination since they provide him the incentives to increase supply, and utilize his effort disutility costs (which increase with quantity supplied) to limit it at the optimum quantity. This explains the observation that some firms compensate operations managers based on sales and fill rate (which is a measure derived from backorders alone). We thus show that simply choosing the right performance metrics can mean the difference between aligning the interests of the salesforce with that of the firm and not being able to do so, while still keeping the contracts very simple.

We also consider how the reward structure for the coordinating contracts varies across different industries with product and demand characteristics. We find that as the variance in demand increases, the sales manager's commission rate for sales can increase. This happens if inventory costs are large enough because the firm then wants to reduce the chance of having unsold goods by creating incentives for the sales manager to increase demand. This result is in marked contrast to the classic prediction from agency theory that an increase in demand uncertainty will lead to a reduction of sales incentives provided to a risk-averse sales agent. We do not assume agents to be risk-averse, but this helps us to identify other drivers of incentive structure in firms and obtain insights that run contrary to conventional results. This is in the spirit of recent literature in economics on incentives in firms which extends incentive theory beyond the risk-insurance trade-off. (We review this literature in the next section.)

In a multiproduct scenario, when one manager manages several products, the coordinating contracts (after correcting for the distortion discussed above) are fairly complicated, involving multiple variable parts in the compensation contract for each manager and/or constructing complex performance metrics. These contracts can be quite difficult to implement. In the real world, the contracts offered to managers who manage multiple products are fairly simple - they usually involve one variable component, which is determined by a simple aggregate performance measure like total dollar sales, total inventory costs or total fill rate across all products.

For practical considerations, we introduce the above simplifications in the contracts. This introduces a different kind of distortion in the incentives - that of suboptimal allocation of effort across products because the marginal return on effort for the manager differs from the marginal profit for the firm for the different products - and the firm cannot achieve the coordinated outcome when it employs one marketing manager for all products and one operations manager for all products (we call this a minimal organization). We consider two extensions of the minimal organization: (1) a 
sales-focused organization, where the firm employs a separate marketing manager for each product (each compensated on the sales for her product) and one logistics manager for all products (compensated on an aggregate metric like total backorders), and (2) an operations-focused organization, where the firm employs one marketing manager for all products (compensated on an aggregate metric like total dollar sales) and a separate operations manager for each product (each compensated on the backorders for his product). In other words, the firm's choice is to finely control one side but to settle for a distortion on the other to limit the size of the salesforce.

We numerically show for a two-product case that, under different conditions, the better design choice can achieve near coordination (99\% of first-best profit), while the wrong design choice in the same scenario might lower profits immensely (over $50 \%$ deviation from the first-best). We consider a wide range of parameters and show that opting for the better of either a sales-focused organization or an operations-focused organization can achieve performance very close to first-best (mean deviation $0.84 \%$ ); always restricting to one specific design leads to a substantial difference from first-best (mean deviation $4.5 \%$ ); while restricting to a minimal organization leads to much higher deviations from first-best (mean deviation 22.0\%). These results suggest that most firms will have either a sales-focused organization or an operations-focused organization based on product and demand characteristics. This is in line with the observation that most firms either have a "sales image" or a "cost image". These results provide some insight into how the underlying objective of aligning marketing and operations, while keeping the size of the salesforce small and compensation contracts simple, can influence the organization of a firm.

The rest of the paper is organized as follows. In Section 2, we review the relevant literature on the marketing-operations management interface and on applications of agency theory in marketing. In Section 3, we consider the case of one-product, show the distortion in incentives when rudimentary performance metrics are used, and propose metrics (and associated contracts) to correct the distortion. In Section 4, we consider the case of two products. We conclude in Section 5. All proofs for the one product case are provided in the appendix at the end of the paper. The two-product case is analyzed in detail in a supplement accompanying this document.

\section{Literature Review}

In this section, we first review the literature that lies at the interface of marketing and operations management, and then review the applications of agency theory to salesforce compensation in marketing. Finally, we review some recent developments in agency theory in economics that have not yet seen applications in marketing, but are relevant to our paper.

The literature at the marketing-operations management interface can be broadly classified into two streams: (1) intra-firm coordination between marketing and operations to increase firm profit and competitiveness (our paper falls in this category), and (2) inter-firm coordination where typically supply-chain partners like manufacturers and retailers want to harmonize channel performance. In the intra-firm coordination category, a stream of research focuses on centralized coordination. De Groote (1994) and Netessine and Taylor (2007) study the simultaneous choice of 
product diversity and production technology for a firm and show that considering the two together can lead to insights that differ greatly from those generated when they are considered in isolation. Souza, Bayus and Wagner (2004) study how the frequency of new product introductions by a firm changes with market demand uncertainty and the cost structure and inventory policy of the firm. Balasubramanian and Bhardwaj (2004) offer a very different perspective from the rest of the literature. They show that in a duopoly setting, coordinating the two functions can be a strategic choice, since firms with coordinated marketing and operations functions compete more intensely than firms that leave them uncoordinated. None of these papers models decentralized coordination using incentive plans offered to the firms' salesforce, which is the focus of our paper.

A paper closely related to ours is Porteus and Whang (1991). They consider a firm with multiple marketing managers, each selling her own product, and a manufacturing manager whose job is to enhance total capacity for production. In the optimal incentive plan they propose, the marketing managers also make the production quantity decisions for their respective products, and are made residual claimants for the contributions from their products. Our work differs in a number of ways. We assume that the firm is free from capacity considerations and delegates the supply decision (analogous to the production quantity decision made by the marketing manager in their model) to the operations manager. Under this assumption, we show that the firm cannot achieve coordination based on commonly used performance measures. We then propose the performance metrics the firm must use and the contracts it should offer to the marketing and operations managers to achieve coordination. We also show how the coordinating contracts vary by product and demand characteristics. Second, in the extension of our basic model to multiple products, we endogenize the decision of the structure of the organization, something that they treat as exogenous.

In the inter-firm coordination category, the typical scenario is that of an upstream supplier or manufacturer supplying to a downstream distributor or retailer. The contracts here are between these two entities (as opposed to the intra-firm coordination case, where the firm contracts with marketing and operations managers, and there is no direct exchange between the managers) and the goal is to coordinate activities like product delivery and information transfer, typically by leveraging instruments like wholesale price, revenue sharing agreements and return policies. There is a huge literature on inter-firm coordination in both marketing (Jeuland and Shugan 1983, Moorthy 1987, Desai, Koenigsberg and Purohit 2004, and references therein) and operations management (Cachon 2003, and references therein). At the interface of the two streams, Eliashberg and Steinberg (1987) characterize the dynamic behavior (as impacted by seasonality of demand) of the distributor's pricing, processing and inventory policies, and the manufacturer's production and inventory policies. Netessine and Rudi (2004) analyze the case of "drop-shipping" where an Internet-based retailer advertises to acquire customers, but all the inventory is held by the manufacturer who is also responsible for shipping out the product after customers place their orders. They show how transferring the inventory risk to the manufacturers leads to a new set of issues in the supply chain, and characterize coordinating contracts for this new structure. Since the focus of our paper is on intra-firm coordination, we refer the reader to these two papers for comprehensive literature 
reviews.

Basu, Lal, Srinivasan and Staelin (1985) were the first to apply the agency paradigm from economics to the problem of salesforce compensation in marketing and discuss the impact of uncertainty, risk aversion, sales response effectiveness and other factors on compensation plans. Lal and Staelin (1986) extend this framework to a menu of contracts for heterogenous salesforces, and Lal and Srinivasan (1993) extend it to the case of multiple products. Rao (1990) proposes a menu of quota-based plans for a heterogenous salesforce where the salespersons self-select their plans and shows under which sales environments this scheme is optimal. Raju and Srinivasan (1996) propose a simple quota-based scheme for heterogenous salesforces where only the quota varies across the compensation schemes, and numerically show that for realistic cases performance under this scheme is very close to the performance under optimal plans laid out in Basu et al. (1985). Another stream of literature focuses on designing compensation plans to extract accurate demand forecasts from sales personnel to compensate them appropriately (Gonik 1978, Rao 1990, Celikbas, Shanthikumar and Swaminathan 1999, Chen 2000, Chen 2005), which can also help in planning operations better.

The framework in Basu et al. (1985) has been extended to include price delegation to the salesforce under competition (Bhardwaj 2001), monitoring of the salesforce (Joseph and Thevarajan 1998), including customer satisfaction measures in the performance measures of the salesperson (Hauser, Simester and Wernerfelt 1994) and assuming a risk-averse firm (Misra, Coughlan and Narasimhan 2005). In parallel with the development of theoretical models, several studies in marketing have attempted to empirically validate the theoretical findings, with mixed results. Coughlan and Narasimhan (1992), Lal, Outland and Staelin (1994), Joseph and Kalwani (1998) and Misra et al. (2005) find support for the predictions of agency theory. However, Prendergast (1999) cites several examples from economics literature where empirical studies have failed to confirm theoretical predictions. Ghosh and John (2000) conduct a series of experiments and find mixed support for agency theory.

Almost all papers on salesforce compensation in marketing assume the agent to be risk-averse and rely on the trade-off between incentives and insurance for their main results. Prendergast (2000) argues that while the logic behind this assumption is strong, only weak empirical support has been found for the results it predicts and points out several reasons for which one observes deviations in reality. Similarly, Gibbons (2005) calls for broadening the focus of incentive theory beyond this trade-off and summarizes some recent advances in economics literature, like career concerns and investment in capabilities, that help to explain observed incentive schemes that are unexplained by the risk-incentive trade-off. He points to a very important aspect of incentive contracts observed in the real world - the use of distorted or inappropriate performance measures. Kerr (1975) calls this "the folly of rewarding for A while hoping for B." In a multitasking framework, where an agent has to allocate effort among a number of different tasks (Holmstrom and Milgrom 1991), Baker (2000) shows that, even in the absence of risk aversion, the variable component of the incentive contract will depend on the degree of alignment between what the firm wants the agent to do and what the performance measure of the agent actually measures. He also provides several examples 
where distorted performance measures can induce unintended consequences in organizations. In our analysis in the sections to follow, we show how, in our marketing/operations setting where the firm has to coordinate the decisions of two independent agents, contracting on certain measures like total inventory cost can have the problem of "rewarding for A while hoping for B." To the best of our knowledge, this misalignment of incentives in such an interdependent setting has not been studied yet. Furthermore, we show that simply choosing appropriate performance metrics can coordinate the decentralized marketing and operations units of the firm. Thus, we also add to the growing literature on the marketing/operations management interface.

Finally, there is extensiveliterature in economics and management on organization design, which looks primarily at issues like delegation of decision rights in organizations. We do not review this literature here, since our results on organization design focus on a very different aspect (whether the firm should focus on the sales side or the operations side) and are rooted in trade-offs involved in distorting incentives on either the sales or the operations side.

\section{Model}

\subsection{Model Description and Notation}

We model a firm selling one product. (In Section 4 we consider a firm selling two products.) The firm (denoted by the subscript $f$; referred to as "it") employs two managers - a marketing manager (or sales manager; denoted by the subscript $m$; referred to as "she") whose job is to provide sales enhancing effort for the product, and an operations manager (or logistics manager; denoted by

the subscript $o$; referred to as "he") whose job is to decide the quantity of product supplied. The demand for the product is denoted by the random variable $D(A)$ defined as

$$
D(A)=A+\mu+\varepsilon
$$

whereby $\mu$ is the mean demand in the absence of sales effort, $A$ is the sales effort which increases the mean demand to $A+\mu$, and uncertainty is incorporated by using an additive random error term $\varepsilon$. Before the selling season begins, only the distribution of demand is known, but the quantity stocking decision has to be made. After demand is realized, the actual sales (denoted by the random variable $Y=\min \{Q, D(A)\}$ ) depend on the quantity stocked $(Q)$ by the operations manager. On the revenues side, for every unit sold the firm obtains revenue $r$. On the costs side, for every unit stocked, a marginal cost $c_{o}$ is incurred. After demand is realized, if the quantity stocked is higher than demand the firm is left with unsold inventory (denoted by the random variable $U=\max \{Q-D(A), 0\}$ ), and incurs a penalty $c_{u}$ per unsold unit. This can be thought of as the remaining goods being salvaged at $r-c_{u}$ per-unit. On the other hand, if the quantity stocked is lower than demand then there are missed sales, leading to backorders (denoted by the random variable $B=\max \{D(A)-Q, 0\})$, and the firm incurs a penalty $c_{b}$ per backorder. This can be thought of as a penalty due to customer dissatisfaction at not being able to obtain the product 
after it was advertised by the marketing manager, or the explicit cost of expediting a shipment. The total inventory cost borne by the firm is denoted by the random variable $C=c_{o} Q+c_{u} U+c_{b} B$.

To employ the managers, the firm has to compensate them for their efforts. We assume that the compensation for each manager consists of a fixed part, called salary, and a variable part, called commission. The commission for a manager is determined using a performance metric for that manager and a predetermined per-unit commission rate. Denoting the salary, the perunit commission rate and the performance metric for the marketing manager by $w_{m}, \alpha_{m}$ and $P_{m}$ respectively, we denote her total compensation by the random variable $S_{m}=w_{m}+\alpha_{m} P_{m}$. Similarly, we denote the total compensation of the operations manager by the random variable $S_{o}=w_{o}+$ $\alpha_{o} P_{o}{ }^{4}$ The performance metrics for the managers can only be observed quantities.

Both managers are effort averse. If the marketing manager exerts sales effort $A$, her disutility of effort is given by the function $V_{m}(A)$ which is assumed to increase in $A$ in a convex manner. (For every extra unit of effort exerted by the marketing manager, she has progressively higher disutility.) On the side of the operations manager, we assume that something can go wrong with a random fraction of all units he stocks, to correct for which he has to exert effort. ${ }^{5}$ If he stocks $Q$ units, a random fraction $\zeta$ requires effort $\chi$, so that the random variable denoting his total effort is given by $\chi Q \zeta$. We assume that $\chi^{2} E\left[\zeta^{2}\right]=\omega^{2}$. For simplicity, we refer to $\omega^{2}$ as the variance in stocking effort shocks. As in the case of the marketing manager, we assume that if the operations manager exerts effort $e$, his disutility of effort is given by the function $V_{o}(e)$ which is assumed to be convex in $e$. Hence, the disutility of effort for the operations manager on stocking $Q$ units of inventory is given by the random variable $V_{o}(\chi Q \zeta)$. Therefore, the marketing manager's net utility is given by the random variable $\Pi_{m}=S_{m}-V_{m}(A)$ and the operations manager's net utility is given by the random variable $\Pi_{o}=S_{o}-V_{o}(\chi Q \zeta)$. We also assume that each manager has an outside option, i.e., if he or she chooses not to work with the firm each has a fall-back option that gives him or her a certain level of utility. We normalize this to 0 without any loss of generality. The firm's net profit is given by the random variable $\Pi_{f}=r Y-C-S_{m}-S_{o}$. We have summarized the notation in Table 1.

In our model, we treat the retail price, $r$, as exogenous. This is consistent with the industry practice of determining compensation schemes for managers after the price decision has already been made. In other words, not only are prices usually sticky over time, they are also decided at a

\footnotetext{
${ }^{4}$ It is costly to monitor the sales effort exerted by the marketing manager, so the firm prefers an "outcome-based contract" for her. The aim of contracting with the operations manager using performance measures is to incentivize optimal supply. The quantity supplied is seemingly observable, so that, at least theoretically, it should be possible to write a "behavior-based contract" (or a "forcing contract") to make the logistics manager stock this level of inventory. However, there is sufficient evidence from the industry that logistics managers are offered outcome-based contracts using cost-based performance measures. This can be due to difficulties in implementing the highly nonlinear forcing contracts. There is also literature that shows that excessive monitoring of employees leads to suboptimal performance (Stanton (2000) and references therein). Moreover, we will show that the firm can delegate the supply decision and construct contracts to achieve the first-best solution. We therefore use outcome-based contracts for the rest of the paper for both managers. (For a discussion on behavior-based contracts and outcome based contracts in agency theory, see Anderson and Oliver (1987).)

${ }^{5}$ For instance, this fraction of units might be faulty and he has to replace them, or someone might try to steal them (known as shrinkage), and he has to provide security, etc. This multiplicative form for inventory effort is in accordance with the "inventory inaccuracy" literature (Liu, So and Zhang 2006).
} 


\begin{tabular}{|c|l|}
\hline Symbol & Quantity \\
\hline$r$ & retail price \\
$c_{o}$ & marginal cost of inventory \\
$c_{u}$ & unsold inventory cost \\
$c_{b}$ & backorder cost \\
$A$ & sales effort \\
$Q$ & quantity stocked \\
$D(A)$ & demand when sales effort is $A$ \\
$\mu, \varepsilon$ & mean demand (when $A=0)$ and random error in demand \\
$\zeta$ & random effort exerted for every unit of inventory stocked \\
$Y=\min \{Q, D(A)\}$ & realized sales \\
$U=(Q-D(A))^{+}$ & unsold inventory \\
$B=(D(A)-Q)^{+}$ & backorders \\
$C=c_{o} Q+c_{u} U+c_{b} B$ & inventory cost \\
subscripts $f, m, o$ & denote "firm", "marketing manager" and "operations manager" \\
$S_{m}$ & total salary of marketing manager \\
$S_{o}$ & total salary of operations manager \\
$V_{m}(A)$ & effort disutility function for marketing manager \\
$V_{o}(\chi Q \zeta)$ & effort disutility function for operations manager \\
\hline
\end{tabular}

Table 1: Notation for the model with a firm selling one product

"higher," more strategic, level. Furthermore, in Section 3.4, we determine the impact of price on the optimal contract parameters by conducting comparative statics.

We assume that all agents are risk neutral. As mentioned before, a key assumption of principalagent models in marketing has been the risk aversion of agents. However, there is only lukewarm evidence in favor of the results relying upon the risk-incentive trade-off (Prendergast 2000). We deviate from this assumption and show that in this setting, even when agents are risk neutral, the choice of performance measures that are contracted upon, along with the decentralized nature of decision-making, has interesting implications for the contracts that must be offered to the two managers.

The order of events in the game is as follows. In the first stage, the firm decides the performance measures for the two managers and offers $S_{m}$ and $S_{o}$ as take-it-or-leave-it contracts to the marketing manager and the operations manager respectively. In the second stage, contingent upon their accepting the contracts, the two managers simultaneously make their decisions on sales effort $A$ and quantity $Q$. Then demand is realized, profits appropriated by the firm and compensation paid to the managers. We assume that both managers know each other's contracts and can observe each other's actions. We solve for the subgame perfect outcome of this game, as follows.

Given their contracts, the marketing manager and the operations manager simultaneously solve 
for $A^{*}$ and $Q^{*}$ :

$$
\begin{aligned}
& A^{*}=\arg \max _{A} E\left[\Pi_{m} \mid Q^{*}, A\right]=E\left[S_{m} \mid Q^{*}, A\right]-V_{m}(A) \\
& Q^{*}=\arg \max _{Q} E\left[\Pi_{o} \mid Q, A^{*}\right]=E\left[S_{o} \mid Q, A^{*}\right]-E V_{o}(\chi Q \zeta)
\end{aligned}
$$

Given these values of $A^{*}$ and $Q^{*}$ in terms of the contract parameters, the firm solves for optimal values of $w_{m}, \alpha_{m}, w_{o}, \alpha_{o}$ to maximize its own profits:

$$
\begin{gathered}
\max _{\left\{w_{m}, \alpha_{m}, w_{o}, \alpha_{o}\right\}} E\left[\Pi_{f} \mid Q^{*}, A^{*}\right]=r E\left[Y \mid Q^{*}, A^{*}\right]-E\left[C \mid Q^{*}, A^{*}\right]-E\left[S_{m} \mid Q^{*}, A^{*}\right]-E\left[S_{o} \mid Q^{*}, A^{*}\right] \\
\text { such that: } \max _{A} E\left[S_{m} \mid Q^{*}, A\right]-V_{m}(A) \geq 0 \\
\max _{Q} E\left[S_{o} \mid Q, A^{*}\right]-E V_{o}(\chi Q \zeta) \geq 0
\end{gathered}
$$

where $E\left[X \mid \Omega_{1}, \ldots, \Omega_{k}\right]$ denotes the expected value of the random variable $X$ given the values $\Omega_{1}, \ldots, \Omega_{k}{ }^{6}$ The last two constraints are to ensure that the managers choose to work for the firm when offered the contracts rather than to fall back on their outside options.

\section{$3.2 \quad$ First-Best Outcome}

Consider the case when the firm can dictate to the marketing manager the sales effort and to the operations manager the quantity to be supplied. The firm will dictate to them the optimal decisions and accordingly compensate them for their efforts. This is the best the firm can do - we call it the "first-best" solution and use it as the benchmark, i.e., in the cases when the firm cannot dictate actions to the managers it will strive to design their contracts so that their actions achieve the first-best profit for the firm. In this section, we characterize the unique first-best solution in Proposition 1 with the aid of the lemma below.

Lemma 1 Under the assumptions on demand and effort disutility functions in section 3.1, the first-best solution to the firm's problem, given by the pair $\left(Q^{F B}, A^{F B}\right)$, is unique for any arbitrary distribution of $\varepsilon$.

Proof Refer to Appendix I.

To characterize the first-best solution, we now make the following assumptions for tractability:

1. The error component in demand is distributed as $\varepsilon \sim$ Uniform $[-\sigma, \sigma]$.

2. The disutility of effort of the marketing manager has the form $V_{m}(A)=\frac{1}{2} A^{2}$.

\footnotetext{
${ }^{6}$ To simplify the notation, we will denote $E\left[X \mid \Omega_{1}, \ldots, \Omega_{k}\right]$ by $E X$ from now on. The values $\Omega_{1}, \ldots, \Omega_{k}$ based on which this expected value is determined will be clear by context. Where confusion can arise, we will revert to the full notation.
} 
3. The disutility of effort of the operations manager has the form $V_{o}(e)=\frac{1}{2} e^{2}$. Note that under our assumptions on the effort that the operations manager has to exert and the above disutility of effort function, his expected disutility of effort from stocking $Q$ units will be $E V_{o}(\chi Q \zeta)=\frac{1}{2} \omega^{2} Q^{2}$, which is convex increasing in $Q .{ }^{7}$

Finally, we make the assumption $c_{b} \leq \bar{c}$ where $\bar{c}=\frac{c_{o}\left(r+\omega^{2}\left(r+c_{u}+2 \sigma\right)+c_{u}\left(r-\omega^{2}(\mu-\sigma)\right)\right.}{\omega^{2}\left(r-c_{o}+\mu+\sigma\right)}$. This assumption essentially means that the penalty due to a backorder is less than the sum of marginal cost and penalty from unsold inventory (for any values of the other parameters), and holds true for a typical firm. We discuss this assumption in more detail in Appendix II.

Proposition 1 Under the assumptions above, the first-best solution is given by the unique pair $\left(Q^{F B}, A^{F B}\right)$, where

$$
\begin{aligned}
Q^{F B} & =\frac{\left(r-c_{o}\right)\left(r+c_{u}+c_{b}\right)+\left(r+c_{b}\right)(\mu+\sigma)+c_{u}(\mu-\sigma)-2 c_{o} \sigma}{\left(r+c_{u}+c_{b}\right)\left(1+\omega^{2}\right)+2 \sigma \omega^{2}}, \\
\text { and } A^{F B} & =\frac{\left(r-c_{o}\right)\left(r+c_{u}+c_{b}\right)-\left(\left(r+c_{u}\right)(\mu-\sigma)+c_{b}(\mu+\sigma)\right) \omega^{2}}{\left(r+c_{u}+c_{b}\right)\left(1+\omega^{2}\right)+2 \sigma \omega^{2}} .
\end{aligned}
$$

Proof Refer to Appendix III.

We can verify for the above solution that $A^{F B}+\mu-\sigma \leq Q^{F B} \leq A^{F B}+\mu+\sigma$, i.e., the stocking level is between the maximum and minimum demand that can be realized. Some comparative statics for the above solution will be provided in Section 3.4.

\subsection{Incentive Contracts}

We now assume that the firm offers incentive contracts to the two managers. Based on these contracts, the managers make their decisions to maximize their own net utilities. The aim of the firm is to construct the contracts in such a way that the actions of the two managers, chosen independently and simultaneously, maximize the firm's profits. The construction of the compensation contracts has two elements requiring a decision:

1. Which performance measure should be contracted on for each manager?

2. Given these performance measures, what should be the parameters of the optimal contract for each manager?

In this part of the paper, we show how choosing the right performance measure can mean the difference between being able to incentivize the managers to achieve the first-best solution, and not being able to do so.

\footnotetext{
${ }^{7}$ Using the more general disutility functions $V_{m}(A)=\frac{1}{2} k_{m} A^{2}$ and $V_{o}(e)=\frac{1}{2} k_{o} e^{2}$ does not change any insights. To reduce clutter and simplify the expressions without losing any insights, we fix $k_{m}=k_{o}=1$.
} 


\subsubsection{Contracts using rudimentary metrics}

The sales manager is responsible for exerting effort to increase demand. The operations manager is responsible for stocking inventory to match supply and demand. A natural metric to measure the performance of the sales manager is the number of units sold (or dollar value of the units sold), while a natural metric to measure the performance of the operations manager is the realized total cost (comprising of marginal cost, cost due to unsold inventory and cost due to backorders). Several well-known firms use these metrics to determine the compensation of sales and operations managers, as pointed out in the introductory section (Shapiro 1977, Ellinger et al. 2006). In this section, we use these metrics for the compensation contracts. We determine the optimal linear contracts and show that the firm will not be able to align the interests of the managers with its own interests because the chosen metrics create a distortion in the incentives of the managers.

Formally, $P_{m}=Y$ so that $S_{m}=w_{m}+\alpha_{m} Y$, and $P_{o}=-C$ so that $S_{o}=w_{o}-\alpha_{o} C$. In other words, the compensation structure of the marketing manager includes a fixed salary and a linear piece-rate reward for sales achieved, and the compensation structure of the operations manager includes a fixed salary and a linear piece-rate penalty for total cost. Effectively, the marketing manager will maximize sales and the operations manager will minimize total costs. The following proposition shows that, using contracts of the above form, the firm will be unable to achieve the first-best outcome.

Proposition 2 If the contracts of the sales and operations managers are of the form $S_{m}=w_{m}+$ $\alpha_{m} Y$ and $S_{o}=w_{o}-\alpha_{o} C$ respectively, and $c_{b} \leq \bar{c}$, the firm can never achieve the first-best outcome.

Proof Refer to Appendix IV.

The self-interested actions of the managers will achieve the first-best solution for the firm only if their expected utility functions, under the contracts offered, are concave in their respective actions. If the contracts are of the above form, the condition for concavity of the sales manager's expected utility function always holds, but that for the operations manager's expected utility function never holds. (See the proof in Appendix IV for details.) This implies that the incentives of the operations manager are misaligned. In other words, when the above constraints are not satisfied, the operations manager will go for a solution at the extreme, i.e., stocking zero units of the product, since his utility function is convex rather than concave. Moreover, since the first-best solution is unique, no other solution under this contract can achieve the first-best outcome.

The above analysis implies that the misalignment occurs on the side of the operations manager and not on the side of marketing manager, for the following reason. The two decision variables, sales effort and quantity stocked, are strategic complements. To achieve the first-best outcome, the firm wants both these variables to simultaneously reach the first-best levels. The firm rewards the marketing manager in such a way that her sales effort reaches the first-best level - since she is being paid for sales realized, she will keep putting in effort to increase the expected level of sales, 
up to the point where her disutility from effort becomes very high. Now, the firm ideally wants the operations manager to stock according to the demand created by the marketing manager's effort.

A closer look at the nature of the metric on which he is being penalized (total cost) makes it clear that he does not have sufficient incentive to do so. For every extra unit that he stocks, the total marginal cost increases, the total expected cost from unsold inventory increases (because the expected unsold inventory increases, all else being equal) and the total expected cost due to unmet demand decreases (because the expected unmet demand decreases, all else being equal). He will raise the level stocked only if the total expected cost decreases, which will happen only if the cost of missing a sale is so high that it can offset the cost of purchasing and stocking extra units, on some of which he might even be levied an extra penalty if the actual demand turns out to be low. Since in a typical firm the penalty from lost sales is not so high (which is reflected in our assumption $\left.c_{b} \leq \bar{c}\right)$, the operations manager will not stock the optimal amount. This insight falls very well in line with the impression conveyed in the introductory section that the method of evaluation for the operations side is overly cost focused, and reflects the classic discord between marketing and operations.

In the following sections, we propose performance measures and the corresponding linear contracts to correct this discord.

\subsubsection{Interdependent contracts}

In the previous section, we showed how contracting with the operations manager on total cost will create a distortion in his incentives and prevent the firm from achieving the first-best profit. The distortion in these cases was that the operations manager had a disincentive to stock large enough quantities because the penalty due to cost was very high due to marginal and unsold inventory costs. We now show that if this contract is extended to reward him on the sales achieved, while still keeping the contract linear, the firm can overcome this problem and always structure the compensation scheme to achieve the first-best outcome. Since the firm is using metrics from its sales arm in the compensation contract of the operations arm, we call this an interdependent contract. Formally, the contract of the operations manager is $S_{o}=w_{o}-\alpha_{o} C+\beta_{o} Y$, i.e., he is still being penalized for costs at the rate $\alpha_{o}$, but is also being rewarded for sales at the rate $\beta_{o}$. The contract for the marketing manager is the same, i.e., $S_{m}=w_{m}+\alpha_{m} Y$. The following proposition gives the optimal contracts.

Proposition 3 If the contracts of the sales and operations managers are of the form $S_{m}=w_{m}+$ $\alpha_{m} Y$ and $S_{o}=w_{o}-\alpha_{o} C+\beta_{o} Y$ respectively, the optimal contracts (that achieve the first-best outcome) are characterized by the set of parameters $\left\{w_{m}^{*}, \alpha_{m}^{*}, w_{o}^{*}, \alpha_{o}^{*}, \beta_{o}^{*}\right\}$, where

$$
\begin{aligned}
\alpha_{m}^{*} & =\frac{\left(r-c_{o}\right)\left(r+c_{u}+c_{b}\right)-\left(\left(r+c_{u}\right)(\mu-\sigma)+c_{b}(\mu+\sigma)\right) \omega^{2}}{\left(r-c_{o}\right)+c_{b}\left(1+\omega^{2}\right)-(\mu-\sigma) \omega^{2}}, \\
w_{m}^{*} & =-\alpha_{m}^{*} E\left[Y \mid Q^{F B}, A^{F B}\right]+V_{m}\left(A^{F B}\right),
\end{aligned}
$$


the pair $\left(\alpha_{o}^{*}, \beta_{o}^{*}\right)$ satisfies

$$
\begin{aligned}
\alpha_{o}^{*} & +\left(\frac{c_{o}+r \omega^{2}+c_{u}\left(1+\omega^{2}\right)+(\mu+\sigma) \omega^{2}}{-r\left(c_{o}+c_{u}\right)+\left(r\left(c_{b}-c_{o}\right)-c_{o}\left(c_{u}+c_{b}\right)+c_{b}(\mu+\sigma)+c_{u}(\mu-\sigma)-2 c_{o} \sigma\right) \omega^{2}}\right) \beta_{o}^{*} \\
& =\frac{\left(\left(r-c_{o}\right)\left(r+c_{u}+c_{b}\right)+\left(r+c_{b}\right)(\mu+\sigma)+c_{u}(\mu-\sigma)-2 c_{o} \sigma\right) \omega^{2}}{-r\left(c_{o}+c_{u}\right)+\left(r\left(c_{b}-c_{o}\right)-c_{o}\left(c_{u}+c_{b}\right)+c_{b}(\mu+\sigma)+c_{u}(\mu-\sigma)-2 c_{o} \sigma\right) \omega^{2}}, \\
\text { and } w_{o}^{*} & =\alpha_{o}^{*} E\left[C \mid Q^{F B}, A^{F B}\right]-\beta_{o}^{*} E\left[Y \mid Q^{F B}, A^{F B}\right]+\omega^{2} V_{o}\left(Q^{F B}\right),
\end{aligned}
$$

subject to the conditions $\alpha_{m}^{*}+2 \sigma>0$ and $\alpha_{o}^{*}\left(c_{u}+c_{b}\right)+\beta_{o}^{*}+2 \sigma \omega^{2}>0$.

The firm can always find such a contract.

Proof Refer to Appendix V.a.

Note that the firm can always find a contract of the above form to motivate the managers to achieve the first-best outcome. As already shown in the proof of Proposition 2, the condition $\alpha_{m}^{*}+2 \sigma>0$ is always satisfied. Furthermore, a pair $\left(\alpha_{o}^{*}, \beta_{o}^{*}\right)$ satisfying the conditions in Proposition 3 can always be found. In fact, there is an infinite set of such contracts because any point on the $\left(\alpha_{o}^{*}, \beta_{o}^{*}\right)$ plane that is on the straight line specified above, and satisfies the constraint $\alpha_{o}^{*}\left(c_{u}+c_{b}\right)+$ $\beta_{o}^{*}+2 \sigma \omega^{2}>0$, gives a feasible contract. (See Figure 1 for an example.) Note that this contract works even when the contract with cost penalty alone does not, because his expected reward from higher realized sales offsets the disincentive from supplying a high quantity, and this motivates him to supply more. This reward should be high enough to overcome the cost penalty (and the disutility of effort), which is what the constraint $\alpha_{o}^{*}\left(c_{u}+c_{b}\right)+\beta_{o}^{*}+2 \sigma \omega^{2}>0$ ensures. Furthermore, the operations manager does not stock an excessive amount because the disutility of effort from stocking a higher quantity increases in a convex manner.

While the contracts above achieve coordination, they have two variable parts (penalty for cost and reward for sales), which can make them somewhat difficult to implement. From the infinite set of contracts, the firm may want to choose the simplest contract that can coordinate for any values of the other parameters, possibly a contract with only one variable component. The following corollary characterizes such a contract.

Corollary 3.1 The simplest interdependent contract for the operations manager that achieves the first-best outcome is given by the parameters

$$
\begin{aligned}
\alpha_{o, s}^{*} & =0 \\
\text { and } \beta_{o, s}^{*} & =\frac{\left(\left(r-c_{o}\right)\left(r+c_{u}+c_{b}\right)+\left(r+c_{b}\right)(\mu+\sigma)+c_{u}(\mu-\sigma)-2 c_{o} \sigma\right) \omega^{2}}{c_{o}+r \omega^{2}+c_{u}\left(1+\omega^{2}\right)+(\mu+\sigma) \omega^{2}} .
\end{aligned}
$$

The firm can always find such a contract.

Proof Refer to Appendix V.b. 


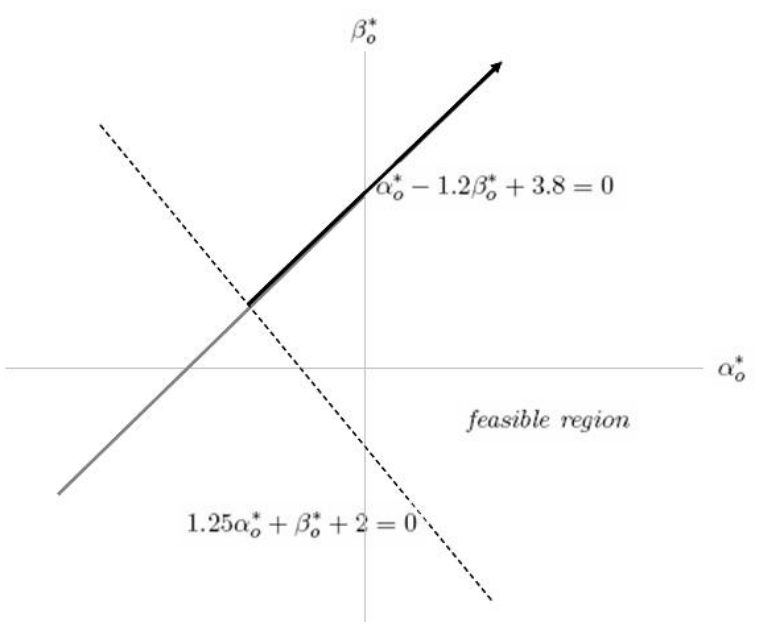

Figure 1: The dark black portion of the straight line represents the set of coordinating interdependent contracts for the operations manager for the case $r=4, c_{u}=0.25, c_{b}=1, c_{o}=1, \mu=\sigma=$ $1, \omega^{2}=1$. The coordinating contracts are given by $S_{m}=-4.18+2.75 Y$ for the marketing manager and $S_{o}=w_{o}^{*}-\alpha_{o}^{*} C+\beta_{o}^{*} Y$ for the operations manager, where $w_{o}^{*}=2.3 \alpha_{o}^{*}-1.74 \beta_{o}^{*}+1.8$ and the pair $\left(\alpha_{o}^{*}, \beta_{o}^{*}\right)$ satisfies the conditions $\alpha_{o}^{*}-1.2 \beta_{o}^{*}+3.8=0$ and $1.25 \alpha_{o}^{*}+\beta_{o}^{*}+2>0$.

Thus, the search for the simplest coordinating contract simply leads to the contract $S_{m}=$ $w_{m}^{*}+\alpha_{m}^{*} Y$ for the marketing manager and the contract $S_{o}=w_{o, s}^{*}+\beta_{o, s}^{*} Y$ for the operations manager. In other words, by compensating both managers on sales alone and appropriately setting the piece-rate rewards the firm can always align their interests with its own.

In effect, the firm corrects the situation in the Section 3.3.1 by changing the performance metric of the operations manager and providing him with an incentive to stock larger quantities. However, to ensure that he stocks no more than the optimal quantity, it sets the reward rate such that, at the first-best stocking level, his marginal reward and the marginal disutility of effort from stocking one more unit are equal. The interesting implication from this analysis is that once an appropriate performance metric has been chosen, not only can the firm achieve the optimum, but the contract that achieves it can have a simple structure.

We note here that this contract is different from a profit-sharing contract. Under a profit-sharing contract, the firm gives a share of the total profit to every agent to align his or her interests with those of the firm. In our setting, however, such a contract does not achieve the first-best solution because the agents will not have the incentive to exert an optimal level of effort, since for every extra unit of effort an agent exerts to increase output, he or she only gets a fraction of this increased output. Since the firm can only observe the aggregate output, the agents prefer to "shirk" rather than "work." This problem has been identified in the literature on group incentive schemes as the "free riding" problem (Nalbantian and Schotter 1997). 


\subsubsection{Information-based contracts}

In the previous section, we demonstrated how extending the contract of the operations manager to include sales metrics along with cost metrics can help to coordinate the managers' actions. In this section, we note that the job of the operations manager is to match supply and demand. Taking a cue from this, we discuss another way of achieving coordination - penalizing him separately for the different components of the mismatch between realized demand and quantity supplied, i.e., imposing one penalty rate if there is unsold inventory and a different penalty rate if there are backorders. Of course, ex post only one of the penalties will come into play, but ex ante both components of the contract need to be specified. Since the implementation of this contract uses detailed information about the components of total cost, we call this an information-based contract. Formally, the contract of the operations manager is $S_{o}=w_{o}-\alpha_{u} U-\alpha_{b} B$. Here, $\alpha_{u}$ denotes a penalty per unsold unit of inventory (if demand is lower than quantity supplied) and $\alpha_{b}$ denotes a penalty per backorder (if demand is higher than quantity supplied). The contract for the marketing manager is the same, i.e., $S_{m}=w_{m}+\alpha_{m} Y$. The following proposition gives the optimal contracts.

Proposition 4 If the contracts of the sales and operations managers are of the form $S_{m}=w_{m}+$ $\alpha_{m} Y$ and $S_{o}=w_{o}-\alpha_{u} U-\alpha_{b} B$ respectively, the optimal contracts (that achieve the first-best outcome) are characterized by the set of parameters $\left\{w_{m}^{*}, \alpha_{m}^{*}, w_{o}^{*}, \alpha_{u}^{*}, \alpha_{b}^{*}\right\}$, where

$$
\begin{aligned}
\alpha_{m}^{*} & =\frac{\left(r-c_{o}\right)\left(r+c_{u}+c_{b}\right)-\left(\left(r+c_{u}\right)(\mu-\sigma)+c_{b}(\mu+\sigma)\right) \omega^{2}}{\left(r-c_{o}\right)+c_{b}\left(1+\omega^{2}\right)-(\mu-\sigma) \omega^{2}}, \\
w_{m}^{*} & =-\alpha_{m}^{*} E\left[Y \mid Q^{F B}, A^{F B}\right]+V_{m}\left(A^{F B}\right),
\end{aligned}
$$

the pair $\left(\alpha_{u}^{*}, \alpha_{b}^{*}\right)$ satisfies

$$
\begin{aligned}
& \alpha_{u}^{*}+\left(\frac{c_{o}+r \omega^{2}+c_{u}\left(1+\omega^{2}\right)+(\mu+\sigma) \omega^{2}}{r-c_{o}+c_{b}\left(1+\omega^{2}\right)-(\mu-\sigma) \omega^{2}}\right) \alpha_{b}^{*} \\
&=\frac{\left(\left(r-c_{o}\right)\left(r+c_{u}+c_{b}\right)+\left(r+c_{b}\right)(\mu+\sigma)+c_{u}(\mu-\sigma)-2 c_{o} \sigma\right) \omega^{2}}{r-c_{o}+c_{b}\left(1+\omega^{2}\right)-(\mu-\sigma) \omega^{2}}, \\
& \text { and } w_{o}^{*}=\alpha_{u}^{*} E\left[U \mid Q^{F B}, A^{F B}\right]+\alpha_{b}^{*} E\left[B \mid Q^{F B}, A^{F B}\right]+\omega^{2} V_{o}\left(Q^{F B} \zeta\right),
\end{aligned}
$$

subject to the conditions $\alpha_{m}^{*}+2 \sigma>0$ and $\alpha_{u}^{*}+\alpha_{b}^{*}+2 \sigma \omega^{2}>0$.

The firm can always find such a contract.

Proof Refer to Appendix VI.a.

The firm can always find an information-based contract to motivate the managers to achieve the first-best outcome, because a pair $\left(\alpha_{u}^{*}, \alpha_{b}^{*}\right)$ satisfying the conditions in Proposition 4 can always be found. (As before, the condition $\alpha_{m}^{*}+2 \sigma>0$ is always satisfied.) In fact, by the same argument as before, there is an infinite set of such contracts. (See Figure 2 for an example.) To see why this contract can incentivize the operations manager to achieve the first-best outcome even when 


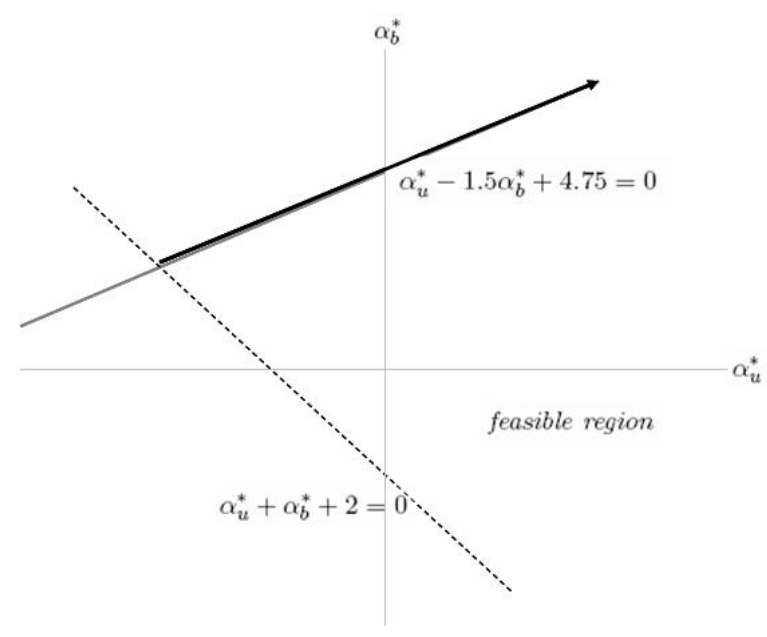

Figure 2: The dark black portion of the straight line represents the set of coordinating informationbased contracts for the operations manager for the case $r=4, c_{u}=0.25, c_{b}=1, c_{o}=1, \mu=\sigma=$ $1, \omega^{2}=1$. The coordinating contracts are given by $S_{m}=-4.18+2.75 Y$ for the marketing manager and $S_{o}=w_{o}^{*}-\alpha_{u}^{*} U-\alpha_{b}^{*} B$ for the operations manager, where $w_{o}^{*}=0.16 \alpha_{u}^{*}+0.36 \alpha_{b}^{*}+1.8$ and the pair $\left(\alpha_{u}^{*}, \alpha_{b}^{*}\right)$ satisfies the conditions $\alpha_{u}^{*}-1.5 \alpha_{b}^{*}+4.75=0$ and $\alpha_{u}^{*}+\alpha_{b}^{*}+2>0$.

the contract based on total cost cannot, we note that as the operations manager stocks more the expected unsold inventory increases and the expected backorders decrease, all else being equal. If the penalty per backorder is large enough to overcome the penalty per unsold unit (and the disutility of effort), the operations manager has an incentive to increase the amount stocked. This is what the constraint $\alpha_{u}^{*}+\alpha_{b}^{*}+2 \sigma \omega^{2}>0$ ensures. Furthermore, the operations manager does not stock an excessive amount because the disutility of effort from stocking a higher quantity increases in a convex manner.

Once again, from this infinite set of contracts, the firm may prefer to choose the simplest contract that can coordinate for any values of the exogenous parameters. The following corollary characterizes such a contract.

Corollary 4.1 The simplest information-based contract for the operations manager that achieves the first-best outcome is given by the parameters

$$
\begin{aligned}
\alpha_{u, s}^{*} & =0 \\
\text { and } \alpha_{b, s}^{*} & =\frac{\left(\left(r-c_{o}\right)\left(r+c_{u}+c_{b}\right)+\left(r+c_{b}\right)(\mu+\sigma)+c_{u}(\mu-\sigma)-2 c_{o} \sigma\right) \omega^{2}}{c_{o}+r \omega^{2}+c_{u}\left(1+\omega^{2}\right)+(\mu+\sigma) \omega^{2}} .
\end{aligned}
$$

The firm can always find such a contract.

Proof Refer to Appendix VI.b.

Thus, the search for the simplest coordinating contract simply leads to the contract $S_{m}=$ $w_{m}^{*}+\alpha_{m}^{*} Y$ for the marketing manager and the contract $S_{o}=w_{o}^{*}-\alpha_{b, s}^{*} B$ for the operations 
manager. In other words, by compensating the marketing manager on sales alone and the operations manager on backorders alone and appropriately setting the piece-rates, the firm can always align their interests with its own. This is a very surprising result because the firm needs to set the penalty appropriately only on one component of cost to achieve coordination, when actually it has three components (marginal cost, unsold inventory cost and backorder cost). In fact, as we saw earlier, if the operations manager is compensated on the total cost, the firm cannot achieve coordination. Basically, by not having variable compensation depend on components of total cost that increase with quantity stocked, the firm removes the disincentive associated with a large stocking quantity. Having removed this distortion in the performance metric, it can set the piece-rate on backorders in such a way that, for the operations manager, the trade-off between the reward for reducing lost sales and extra effort leads to the optimal quantity being stocked. Validation is lent to this result by the fact that in reality many firms compensate their operations managers on backorders-based

measures like fill rate (which is defined as fill rate $=1-\frac{\text { backorders }}{\text { mean demand }}$, and is derived only from backorders, ignoring the other components of cost), as discussed in Cohen et al. (2006).

The literature on compensation of teams identifies that when agents with different skill sets work cooperatively, they prefer that their monetary compensations depend upon performance metrics that are closely related to their work profile so that they do not suffer due to free riding by others (Shaw and Schneier 1995, Sarin and Mahajan 2001). In this light, and recognizing the fact that sales managers and operations managers have very different skill sets (Shapiro 1977), a firm could prefer information-based contracts for coordination, since they compensate the sales manager based on sales and the operations manager based on backorders.

Note that in all the contracts that we consider, the contract for the sales manager is of the form $S_{m}=w_{m}+\alpha_{m} Y$, and does not lead to any coordination problems (unlike the contract for the operations manager). This indicates that sales commission is a robust way to incentivize the sales arm and offers an explanation for the widespread prevalence of this scheme of compensation. Note, however, that the key to using a sales commission scheme properly is to ensure that, at the optimum selling effort, the marginal expected gain for the sales manager from increasing sales is exactly offset by the marginal disutility of sales effort.

\subsection{Comparative Statics}

We now study how the optimal contracts vary with the exogenous parameters of the model, e.g., retail price, marginal cost, unsold inventory cost, backorder cost, variance of the demand distribution and variance of the stocking effort shocks. We choose the simplest optimal contracts, i.e., from interdependent contracts we choose the contract that rewards both managers on sales, and from information-based contracts we choose the contract that rewards the marketing manager on sales and penalizes the operations manager on backorders alone.

Table 2 summarizes the comparative statics for the piece-rates/penalties and other quantities of interest, e.g., total compensation paid to the marketing and operations managers, and the first-best 


\begin{tabular}{c||cc|cc|cc}
\multicolumn{1}{c||}{} & \multicolumn{2}{|c|}{} & \multicolumn{2}{c|}{ Expected } & \multicolumn{2}{c}{ Coordinated } \\
& \multicolumn{2}{|c|}{ piece-rates } & \multicolumn{2}{c}{ total compensations } & \multicolumn{2}{c}{ decision variables } \\
& $\alpha_{m}^{*}$ & $\beta_{o}^{*}, \alpha_{b}^{*}$ & $S_{m}$ & $S_{o}$ & $A^{F B}$ & $Q^{F B}$ \\
\hline \hline$r$ & + & + & + & + & + & + \\
$c_{o}$ & - & - & - & - & - & - \\
$c_{u}$ & + & - & + & - & + & - \\
$c_{b}$ & - & + & - & + & - & + \\
$\sigma$ & $+/-$ & $-/+$ & $+/-$ & $-/+$ & $+/-$ & $-/+$ \\
$\omega$ & - & + & - & $-/+$ & - & -
\end{tabular}

Table 2: Comparative statics for the optimal piece-rates, expected total compensation for the marketing and operations managers, optimal sales effort and optimal quantity stocked, with respect to retail price, marginal cost, penalty from unsold inventory, penalty from backorders, variance in demand and variance in stocking effort shocks.

levels of sales effort and quantity stocked (which the coordinating contracts also achieve).

Variation with $r$ and $c_{o}$ : As the retail price increases, the firm wants to sell more, which means that the optimal sales effort increases. The optimal quantity stocked also increases in tandem with it. Since the salaries for the managers compensate for their respective efforts, the salaries also increase with $r$. For every unit sold, $\alpha_{m}^{*}$ is the reward for the marketing manager, so to increase his effort level (when $r$ increases), this reward must go up, as Table 2 shows. Finally, $\beta_{o}^{*}$ is the reward per-unit sold (under interdependent contracts) and $\alpha_{b}^{*}$ is the penalty per backorder or penalty per lost sale (under information-based contracts) for the operations manager, both of which increase if the firm wants to induce higher sales.

The variation with marginal cost $c_{o}$ is simply in the opposite direction for every case, since marginal cost has the opposite effect on profits as compared to retail price.

Variation with $c_{u}$ and $c_{b}$ : First note that under the first-best outcome, the quantity stocked is between the minimum and maximum levels of demand given the sales effort. As the penalty from unsold inventory $\left(c_{u}\right)$ increases, the firm wants to reduce the expected level of unsold inventory by increasing the mean demand so that $A^{F B}$ increases (treating stocking level as constant) and decreasing the amount stocked so that $Q^{F B}$ decreases (treating sales effort as constant). The marketing manager exerts sales effort, so the firm must increase the reward for sales to her, and thus $\alpha_{m}^{*}$ increases with $c_{u}$. As she exerts more effort, her total compensation also increases. The operations manager decides the quantity to be stocked, so the firm must decrease the reward for sales (or decrease the penalty from lost sales) for him, and thus $\beta_{o}^{*}$ and $\alpha_{b}^{*}$ decrease with $c_{u}$. As he exerts less effort, his total compensation also decreases.

The variation with backorder cost $c_{b}$ is simply in the opposite direction for every case, since as $c_{b}$ increases the firm wants to reduce the level of lost sales, which happens if $A^{F B}$ is reduced (treating stocking level as constant) and $Q^{F B}$ is increased (treating sales effort as constant). 
Variation with $\sigma$ : An increase in the uncertainty in demand $(\sigma)$ (holding all else constant) has different effects based on whether the expression $\left(2 c_{o}+c_{u}-c_{b}\right)-r\left(1-\omega^{2}\right)+\omega^{2}\left(c_{u}-c_{b}\right)+2 \omega^{2} \mu$ is positive or negative. To focus on how costs affect the variation with $\sigma$, assume $\omega^{2}=1$. The above expression then becomes $c_{o}+c_{u}+\mu-c_{b}$. This expression will be negative only if the penalty from backorders is very high. As before, we argue that this will rarely be the case. Then, assuming $c_{o}+c_{u}+\mu-c_{b}>0$ (i.e., "stocking-quantity-related" costs are higher than "lost-salesrelated" costs), we see that, as the uncertainty in demand increases, the firm wants to minimize the chance of having leftover inventory. Consequently, the optimal sales effort increases and the optimal stocking quantity decreases. The results for total compensation follow as before. The piece-rate for sales for the marketing manager increases (to incentivize more sales effort) and the piece-rate for the operations manager decreases (to incentivize a lower stocking quantity). In the other case, when the penalty from backorders is very high, we have $c_{o}+c_{u}+\mu-c_{b}<0$. The firm then wants to minimize the chance of losing a potential sale and all the above effects are reversed.

The results above on piece-rates are in stark contrast to, but complementary to, the results from the classic risk-incentive model, in which an increase in uncertainty in demand always implies a decrease in the piece-rate for the sales agent. In our model, the piece-rate for the marketing manager (responsible for sales effort) can either increase or decrease when uncertainty in demand increases, based on the interplay between mismatch costs on the inventory side (and the piece-rate for the operations manager changes in the opposite direction).

If we do not assume that $\omega^{2}=1$, the insights remain very similar. Note that the expression can be rearranged as $2 c_{o}+c_{u}-c_{b}-r+\omega^{2}\left(r+c_{u}-c_{b}+2 \mu\right)$. It is easy to see that if the "costsof-stocking-inventory-related" parameters $\left(c_{o}, c_{u}, \omega^{2}\right)$ are large, the expression is positive. If the "cost-from-losing-a-sale-related" parameters $\left(r, c_{b}\right)$ are large, the expression is negative. All the results and insights above follow. We state the above formally in the following proposition.

Proposition 5 If $2 c_{o}+c_{u}-c_{b}-r+\omega^{2}\left(r+c_{u}-c_{b}+2 \mu\right)>0$, then as the uncertainty in demand increases

(a) the piece-rate reward for sales for the marketing manager increases, and

(b) the piece-rate reward for sales (under interdependent contracts) and the penalty for backorders (under information-based contracts) for the operations manager decrease.

If $2 c_{o}+c_{u}-c_{b}-r+\omega^{2}\left(r+c_{u}-c_{b}+2 \mu\right)<0$, then as the uncertainty in demand increases the effects on piece-rates are reversed.

Variation with $\omega$ : As $\omega$ (or $\omega^{2}$ ) increases, the variance in the random effort required for every unit of inventory stocked increases, which in turn increases the disutility of effort on the part of the operations manager. In other words, as $\omega$ increases, it becomes less and less desirable for the operations manager to stock more (and, therefore, for the firm as well) and the optimal stocking quantity decreases. Sales effort and stocking quantity being complements, the optimal sales effort also decreases. In line with this, the marketing manager's reward for increasing sales decreases, and so does her compensation. The direction of change for the operations manager's 
compensation is more subtle. The optimal quantity stocked decreases, but the effort cost is higher. Hence, his reward for sales (under interdependent contracts) and the penalty for missed sales (under information-based contracts) has to be increased even to motivate him to supply this lower level of quantity. Furthermore, an increase in $\omega$ decreases $Q^{F B}$, but his total compensation (given by

$\left.\frac{1}{2} \omega^{2}\left(Q^{F B}\right)^{2}\right)$ can go up or down with $\omega$ according to whether $\left(r+c_{u}+c_{b}\right)\left(1-\omega^{2}\right)-2 \omega^{2} \sigma$ is positive or negative. Then, if $\omega$ is small, the expression is positive and his compensation increases with $\omega$, while if $\omega$ is large, the expression is negative and his compensation decreases with $\omega$.

\section{Two Products}

When a firm carries more than one product, the distortion in incentives that arises by contracting on total cost with the operations manager discussed in the previous section is present, and can be corrected in the same way. However, we see another distortion, the source of which is that one marketing manager now has to allocate her selling effort among several products and, similarly, one operations manager has to allocate his supplying effort among several products. These allocations will be suboptimal for the firm if incentives are not properly aligned (Baker 2000). In this section, we study this distortion and show how it leads a firm to focus more on either its sales arm or its operations arm. The technical details for the two-product case have been provided in a supplement accompanying this document.

In the model, the only difference from the one-product case lies in the demand system, since the demand for the two products can now be related. We assume that effort exerted to promote one product has an adverse effect on the demand for the other product. We incorporate this by using the demand system

$$
D_{i}\left(A_{i}, A_{j}\right)=A_{i}-\theta A_{j}+\mu_{i}+\varepsilon_{i}, j=3-i
$$

where $i \in\{1,2\}$ denotes the $i^{\text {th }}$ product and $0 \leq \theta<1$.

\subsection{Coordinating Contracts}

Consider the case when every product has its own marketing manager and its own operations manager. Clearly, the lack of sufficient incentives to supply the optimal quantity that arises from contracting with the operations manager on total cost will be seen in the two-product case as well. However, as in the one-product case, the firm can always achieve coordination by using either interdependent contracts or information-based contracts, even when the demand for the products is related (as in (4)). Furthermore, contracting with the operations manager only on sales (the simplest interdependent contract) or only on backorders (the simplest information-based contract) can also always achieve the first-best outcome for the firm. We formalize this result in Proposition S.1 in the supplement.

Note, however, that for the above result we have assumed that the firm employs separate managers to sell and supply each product. Suppose now that the managers have to multitask, 
i.e., one marketing manager manages both products and/or one operations manager manages both products, and the firm uses an interdependent contract or an information-based contract for the operations manager. The firm can still structure the contract to achieve the first-best outcome, but the coordinating contract in the most general case is complex, in one of the following two ways.

1. The contracts for both the sales and operations managers have a separate variable component for each product.

2. The performance metrics contracted upon are a specific weighted combination of the metrics for each product. (When sales are contracted upon, these weights may not simply be the retail prices, and when backorders are contracted upon, these weights may not simply be the backorder costs for the products.) In other words, contracting on simple aggregate measures like the total dollar sales or total backorder costs cannot achieve the first-best outcome.

We provide a mathematical justification for the above argument in Appendix S.II of the supplement.

\subsection{Simple contracts and implications for organization design}

In the real world, we usually observe that even when one person manages more than one product, the compensation plan has a single variable component, and the measures contracted upon to determine this variable component are simple measures, e.g., the total dollar value of sales achieved. This is contrary to the two conditions laid out in the previous section.

Under these practical considerations, we now make the following assumptions.

1. The firm wants to employ as few managers as possible, but not to go "too far" from the first-best solution.

2. The firm wants to keep the contracts simple. This means that (a) for every manager there should only be one variable component in the salary, and (b) the performance metric that determines this variable component should be a simple aggregate metric, e.g., the total dollar sales of the two products.

Under these simple contracts, the firm cannot achieve the first-best outcome in the most general case. One agent makes more than one decision and, from the perspective of the firm, there is an optimal level for each decision. However, under the simple contract offered, the marginal return from effort for the manager differs from the marginal profit for the firm for the two products. Therefore, the incentives of the managers are misaligned - the effort allocation between the two products that best pays each manager does not best pay the firm. This distortion, tied to the phenomenon of multitasking, is the problem identified in Baker (2000).

What should the firm do to alleviate this problem? Should it always go with one manager for every job? Clearly, we do not see that in the real world and often observe that one employee manages more than one product. What we do see, however, is that firms usually have either a "sales image," i.e., they focus on the sales side and have more employees working as sales managers 


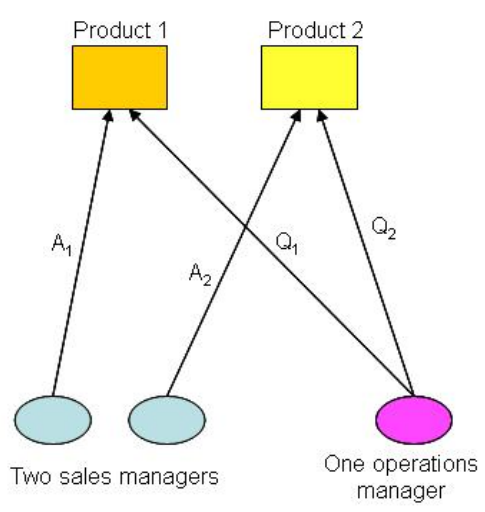

(a) sales-focused organization

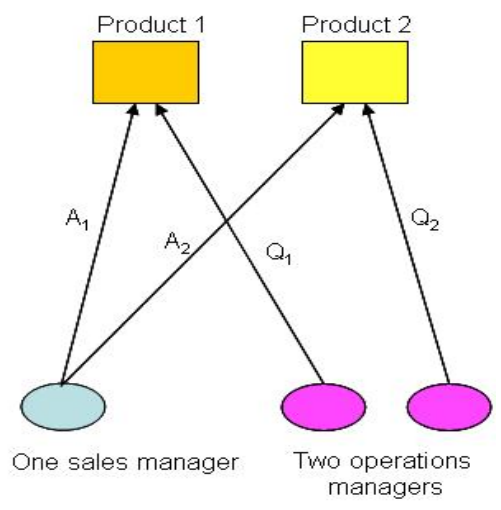

(b) operations-focused organization

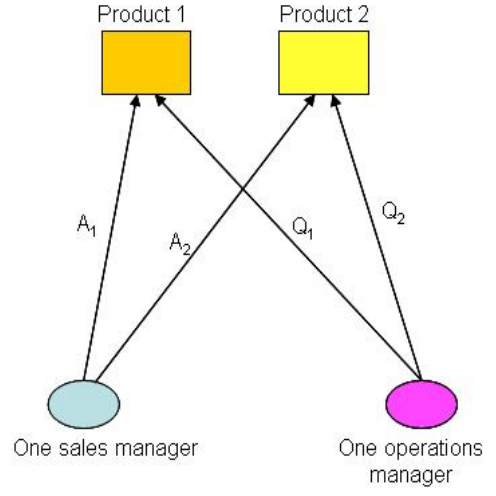

(c) Minimal organization

Figure 3: Schematic representation of the sales-focused, operations-focused and minimal organizations.

than employees managing operations, or they have a "cost image," i.e., they focus on the costs side and have more employees managing operations. To explain these observations, we propose that the firm can opt for one of the following three forms of organization ${ }^{8}$ :

1. sales-focused organization: Under this organization scheme, the firm opts for more flexibility on the sales side and has two sales managers (one for each product) and one operations manager. Figure 3(a) shows a schematic representation of this design.

2. operations-focused organization: Under this organization scheme, the firm opts for more flexibility on the operations side and has two operations managers (one for each product) and one sales manager. Figure 3(b) shows a schematic representation of this design.

3. Minimal organization: Under this organization scheme, the firm has one sales manager and one operations manager. Figure 3(c) shows a schematic representation of this design.

The firm's choice is between finely controlling one side but settling for a distortion on the other to limit the size of the salesforce. Under a sales-focused design, the sales managers decide the sales efforts for their respective products while the operations manager jointly decides the quantity stocked for each product. The sales levels are close to first-best, but both stocking quantities are distorted away from first-best - one product is stocked above the optimal level and the other is stocked below the optimal level. Under an operations-focused design, sales are similarly skewed, but the stocking levels are close to optimal. Based on the product and demand characteristics for the two products, distortions in either the sales arm or the operations arm will harm the firm, so it will prefer the one out of these two organizational structures that minimizes that harm. The point of interest here is how close the firm can get to the first-best outcome using one of these structures.

\footnotetext{
${ }^{8}$ We restrict ourselves to contracts on sales only for both managers (information-based contracts can achieve the same outcomes, so the choice does not matter). This approach already removes the distortion due to contracting on total costs discussed earlier.
} 
Following the intuition above, we provide below some broad results regarding when the firm will choose a particular design and why. The analytical solutions to the games corresponding to each form of design are intractable, so we resort to a numerical maximization procedure to determine the optimal contract parameters and associated actions for the managers. The purpose of our analysis is to illustrate that a firm can have a strong preference for sales-focused or operations-focused design due to effects rooted in distortions of the incentive structure because of multitasking; characterizing exactly the conditions for preference of one design over another requires a more detailed study, which we propose as a direction for future research.

Numerical analysis: For the numerical analysis, note that the major components of the firm's net profits are the revenues from sales and the salaries of the managers to compensate them for their efforts. We assume marginal costs to be zero so that the retail prices effectively act as margins. The inventory cost due to the mismatch between demand and the quantity stocked is much smaller, for two reasons: (1) this component is determined by the expected difference between quantity supplied and demand (both for unsold inventory and backorders) and these differences are small compared to expected sales, and (2) per-unit costs are lower than per-unit retail prices.

We vary the parameters in the following manner to generate a wide asymmetry between the two products: (1) $\theta \in\{0,0.1,0.2,0.3\}$, (2) $r_{1}=8, r_{2} \in\{5,6,7,8,9,10,11\}$, (3) $\sigma_{1}=2, \sigma_{2} \in$ $\{1,1.5,2,2.5,3\}$, and (4) $\omega_{1}^{2}=1, \omega_{2}^{2} \in\{0.5,0.75,1,1.25,1.5\}$. The values for the other parameters are $c_{u 1}=c_{u 2}=4, c_{b 1}=c_{b 2}=4$ and $\mu_{1}=\mu_{2}=0.1$. The parameter values are chosen to parallel the numerical analysis presented in Netessine and Rudi (2004), who have a related model.

The most important result from our numerical analysis is that the choice of organization design can greatly influence the profits of the firm. Hence, it is important for a firm to correctly decide its "organization focus."

Result 1: Under certain scenarios, the firm has a clear preference for one kind of organization design over the other.

There are several scenarios that we identify where, between a sales-focused and an operationsfocused design, the better choice can lead to a profit that is very close to the first-best profit $(99 \%$ of first-best), but the wrong design choice can lead to greatly lower profits (over $50 \%$ lower than first-best). This result arises because, as mentioned earlier, a sales-focused design distorts the decisions on the operations side while an operations-focused design distorts the decisions on the sales side, and one kind of distortion can lead to a more severe impact than the other. For instance, when $\theta=0.2, r_{1}=8, r_{2}=6, \sigma_{1}=2, \sigma_{2}=3, \omega_{1}^{2}=\omega_{2}^{2}=1$, a sales-focused design can achieve a profit $99 \%$ of the first-best outcome, while an operations-focused design achieves a profit only $40 \%$ of the first-best outcome.

Result 2: For the parameter values considered above, the firm can get very close to the first-best 
outcome when it has the choice of sales-focused or operations-focused design. However, when the firm is restricted to a minimal design, the resulting profit is much farther away from the first-best profit.

Always choosing a minimal design can take the firm very far from the first-best profit (mean deviation $22.0 \%$ ). Always choosing a sales-focused or always choosing an operations-focused design can lead to a substantial difference from the first-best outcome (overall mean deviation 4.5\%). However, choosing the better of sales-focused or operations-focused design for each scenario gives a mean deviation of only $0.8 \%$. This suggests that most firms will opt for either a sales-focused design or operations-focused design and supports the observation pointed out earlier that almost all firms have either a "sales image" or a "cost image." Broadly speaking, when retail prices are low the firm prefers an operations-focused design, because the firm needs to "get it right" on the costs side. If the design is operations-focused, the firm settles for suboptimal sales but can set the stocking quantities such that overall costs are lower. If the design is sales-focused, the firm takes a hit on costs. Since retail prices are low, a little is lost in revenue, while the benefit from cost reduction is more significant.

\section{Conclusions and Future Work}

The results in this paper are two-faceted: we provide a simple and practical solution to the classic marketing and operations coordination problem, and at the same time add to the growing literature on agency theory in economics that focuses on the distortions in incentives that arise due to the use of imperfect performance metrics.

The marketing and operations arms of a firm are interdependent and must work in a coordinated manner, but the discord between them has remained a long-standing problem. A prime reason for this discord is that these units operate in a decentralized manner, and marketing compensation is typically overly focused on increasing demand whereas operations compensation is typically overly focused on reducing costs. We draw upon agency theory to structure salesforce compensation

contracts such that the self-maximizing actions of marketing and operations managers achieve the coordinated outcome.

Our assumption of risk neutrality on the part of the managers deviates from the standard assumptions in the salesforce compensation literature in marketing, but it helps us to focus attention on a largely ignored aspect of salesforce compensation contracts - the appropriateness of the performance measure contracted upon. We start by showing that rewarding the operations manager for reducing total cost leads to suboptimal supply. Under random demand, increasing supply increases the marginal cost and the expected cost from unsold goods, and reduces the expected cost from missed sales. However, the first two components of cost typically dominate the third, and the operations manager therefore does not have sufficient incentive to supply the optimal quantity. This case is therefore another example of "the folly of rewarding for A while hoping for B" (Kerr 1975) - a very natural measure of performance for the operations manager (total cost) is not the right 
measure from the firm's point of view. Consequently, the two managers, who are simultaneously deciding on two variables that are strategic complements, do not move towards the optimal solution together.

This "folly" can be corrected simply by changing the performance measure of the operations manager - by rewarding him for sales (as in the simplest interdependent contract) or penalizing him for backorders (as in the simplest information-based contract). Both these schemes can always achieve coordination since they provide him with the incentives to increase supply, and utilize his effort disutility costs to limit the supply at the optimum level. This result adds to the recent literature in economics on how the alignment between the agent's performance metric and the actual objective of the principal influences the contracts offered (Baker 2000, Gibbons 2005). Moreover, the optimal contracts are still very simple (linear) and easy to implement. The appropriate performance metrics are also simple, but not always a priori very obvious (or even intuitive). For instance, the firm can always achieve the coordinated outcome by penalizing the operations manager only on backorders, while total costs are dependent on (and his supply decision influences) not only backorders but also the number of units stocked and the number of units potentially left unsold.

Furthermore, the contracts might need to be restructured in a specific way. In our case, the distortion was on the side of the operations manager, so the fix was obtained by changing his performance metric. Changing the performance measure of the marketing manager alone (e.g., penalizing her on inventory cost while rewarding her for sales) cannot align the incentives in our model.

The comparative statics for the optimal contract parameters provide several interesting results on how commission rates and compensations for the marketing and operations managers vary with product characteristics (prices and costs), uncertainty in demand and uncertainty in stocking effort shocks. One of our results is that if costs are high, the commission on sales for the sales manager increases with a higher demand uncertainty, a result that is contrary to the conventional result from incentive theory. (Traditional incentive theory assumes that the agent is risk-averse, and shows that the commission rate on sales decreases with an increase in uncertainty in demand.) The fact that we abstract away from the risk-aversion assumption helps us to identify other factors (e.g., costs) that drive commission rates in the opposite direction when the firm needs to coordinate its sales and operations arms.

In reality, one would expect both forces (risk-aversion and impact of costs) to work simultaneously, and the observed direction of change will be determined by the one that dominates. This can be an explanation for why several studies have found only lukewarm empirical support for the results predicted by the risk-insurance trade-off (Prendergast 1999). Our results, therefore, also add to the recent stream of literature in economics on incentive theory that aims to explain why variable compensation is often seen to increase with uncertainty in demand (Prendergast 2000).

Our analysis for the multiproduct case focuses on distortions in incentives due to multitasking. Our analysis provides insights into how the underlying objective of aligning marketing and operations, while keeping the size of the salesforce small and compensation contracts simple, can induce 
a clear preference between a sales-focused design and an operations-focused design for different firms.

We generate a number of hypotheses that can be tested using industry data. Our model predicts that firms that manage their operations units using cost-based measures will experience more frequent marketing/operations coordination failures than firms that use service measures like sales achieved or fill rate. The comparative statics in Section 3.4 provide several hypotheses regarding how the optimal commission rates and total compensation for marketing and operations managers vary with product and demand characteristics. (Due to space considerations, we refrain from repeating them here.) The numerical analysis in the multiproduct case predicts that if costs are high compared to per-unit revenue, the firm will move towards an operations-focused design. We have already provided anecdotal evidence supporting several of the above hypotheses; as suitable data become available they can be tested formally.

Finally, our work is not without its shortcomings. For tractability, we have not introduced the assumption of risk-aversion on the part of the managers. Incorporating this assumption will change the optimal contracts offered (the firm will not be able to achieve the first-best outcome, and will reduce the variable components of the compensations). However, the insights that total cost is an inappropriate performance metric, insights that interdependent contracts and informationbased contracts provide the incentives to supply a higher quantity, insights regarding the effect of costs and other parameters on commission rates and insights on preference between sales-focused and operations-focused design will all remain intact. Our model also assumes that the operations manager can supply any quantity seamlessly and without delay. In reality, production or ordering is done in batches using models for inventory control (like the Economic Order Quantity (EOQ) model, or the (Q, r) model), and there is a lead time. Once again, the insight that compensation based on reducing total cost will lead to suboptimal supply will be robust to this variation. In the current model, the problem lies only on the operations side. There can be scenarios, however, when the marketing manager's being overly demand-focused can cause distortions away from the first-best outcome. For example, it is possible that when supply occurs in batches, the marketing manager generates excess demand, but it is not in the firm's interests to order an extra batch of goods to meet this excess demand.

Notwithstanding these limitations, our work provides significant insights into the causes of the discord between marketing and operations and the importance of optimally structuring salesforce compensation schemes to bring the two arms into alignment. 


\section{References}

Anderson, Erin and Richard L. Oliver (1987), "Perspectives on Behavior-Based versus OutcomeBased Salesforce Control Systems," Journal of Marketing, 51 (4), October 1987, 76-88.

Baker, George (2000), "The Use of Performance Measures in Incentive Contracting," The American Economic Review, 90 (2), May 2000, 415-420.

Balasubramanian, Sridhar and Pradeep Bhardwaj (2004), "When Not All Conflict Is Bad: ManufacturingMarketing Conflict and Strategic Incentive Design," Management Science, 50 (4), April 2004, $489-502$.

Basu, Amiya K., Rajiv Lal, V. Srinivasan and Richard Staelin (1985), "Salesforce Compensation Plans: An Agency Theoretic Perspective," Marketing Science, 4 (4), Fall 1985, 267-291.

Bhardwaj, Pradeep (2001), "Delegating Pricing Decisions," Marketing Science, 20 (2), March 2001, 143-169.

Cachon, Gerard (2003), "Supply chain coordination with contracts," Handbooks in Operations Research and Management Science: Supply Chain Management, Steve Graves and Ton de Kok, Eds., North Holland.

Celikbas, Muruvvet, J. G. Shanthikumar and J. M. Swaminathan (1999), "Coordinating production quantities and demand forecasts through penalty schemes," IEEE Transactions, 31 (3), $851-864$.

Chen, Fangruo (2000), "Sales-Force Incentives and Inventory Management," Manufacturing \& Service Operations Management, 2 (2), Spring 2000, 186-202.

Chen, Fangruo (2005), "Sales-Force Incentives, Market Information, and Production/Inventory Planning," Management Science, 51 (1), January 2005, 60-75.

Cohen, Morris A., Narendra Agrawal and Vipul Agrawal (2006), "Winning in the Aftermarket," Harvard Business Review, 84 (5), May 2006, 129-138.

Coughlan, Anne T. and Chakravarthi Narasimhan (1992), "An Empirical Analysis of Salesforce Compensation Plans," Journal of Business, 65 (1), Jan 1992, 93-121.

De Groote, Xavier (1994), "Flexibility and Marketing/Manufacturing Coordination," International Journal of Production Economics, 36, 153-167.

Delaney-Klinger, Kelly, Kenneth K. Boyer and Mark Frohlich (2003), "The return of online grocery shopping: A comparative analysis of Webvan and Tesco's operational methods," The TQM Magazine, 15 (3), 2003, 187-196. 
Desai, Preyas, Oded Koenigsberg and Devavrat Purohit (2004), "Strategic Decentralization and Channel Coordination," Quantitative Marketing and Economics, 2(1), 2004, 5-22.

Eliashberg, Jehoshua and Richard Steinberg (1987), "Marketing-Production Decisions in an Industrial Channel of Distribution," Management Science, 33 (8), August 1987, 981-1000.

Ellinger, Alexander E., Scott B. Keller and John D. Hansen (2006), "Bridging the Divide between Logistics and Marketing: Facilitating Collaborative Behavior," Journal of Business Logistics, 27 (2), 2006, 1-27.

Fisher, Robert J., Elliot Maltz and Bernard J. Jaworski (1997), "Enhancing Communication between Marketing and Engineering: The Moderating Role of Relative Functional Identification," Journal of Marketing, 61 (3), 1997, 54-70.

Ghosh, Mrinal and George John (2000), "Experimental Evidence for Agency Models of Salesforce Compensation," Marketing Science, 19 (4), Fall 2000, 348-365.

Gibbons, Robert (2005), "Incentives Between Firms (and Within)," Management Science, 51 (1), January 2005, 2-17.

Gonik, Jacob, "Tie salesmen's bonuses to their forecasts," Harvard Business Review, 56 (3), May/June 1978, 116-123.

Harps, Leslie Hansen (2002), "Making Dollars \& Sense Out of Logistics," http://www.inboundlogistics.com/articles/features/0302_feature02.shtml.

Hauser, John, Duncan Simester and Birger Wernerfelt (1994), "Customer Satisfaction Incentives," Marketing Science, 13 (4), Fall 1994, 327-350.

Hausman, Warren H., David B. Montgomery and Aleda V. Roth (2002), "Why should marketing and manufacturing work together? Some exploratory empirical results," Journal of Operations Management, 20 (3), 2002, 241-257.

Ho, Teck H. and Christopher S. Tang (2004), "Introduction to the Special Issue on Marketing and Operations Management Interfaces and Coordination," Management Science, 50 (4), April 2004, 429-430.

Holmstrom, Bengt and Paul Milgrom (1991), "Multitask Principal-Agent Analyses: Incentive Contracts, Asset Ownership, and Job Design," Journal of Law, Economics, $E$ Organization, 7, 1991 (Special Issue), 24-52.

Jeuland, Abel P. and Steven M. Shugan (1983), "Managing Channel Profits," Marketing Science, 2(3), Summer 1983, 239-272.

Joseph, Kissan and Manohar U. Kalwani (1998), "The role of bonus pay in salesforce compensation plans," Industrial Marketing Management, 27 (2), March 1998, 147-159. 
Joseph, Kissan and Alex Thevarajan (1998), "Monitoring and Incentives in Sales Organizations: An Agency-Theoretic Perspective," Marketing Science, 17 (2), Feb 1998, 107-123.

Kerr, Steven (1975), "On the Folly of Rewarding for A while Hoping for B," Academy of Management Journal, 18 (4), December 1975, 769-783.

Lal, Rajiv, Donald Outland and Richard Staelin (1994), "Salesforce Compensation Plans: An Individual Level Analysis," Marketing Letters, 5 (2), April 1994, 117-130.

Lal, Rajiv and V. Srinivasan (1993), "Compensation Plans for Single- and Multi-Product Salesforces: An Application of the Holmstrom-Milgrom Model," Management Science, 39 (7), July 1993, 777-793.

Lal, Rajiv and Richard Staelin (1986), "Salesforce Compensation Plans in Environments with Asymmetric Information," Marketing Science, 5 (3), Summer 1986, 179-198.

Liu, Shaoxuan, Kut C. So and Fuqiang Zhang (2006), "Effects of Inventory Inaccuracy in Joint Marketing and Inventory Decisions," working paper, University of California, Irvine.

Misra, Sanjog, Anne T. Coughlan and Chakravarthi Narasimhan (2005), "Salesforce Compensation: An Analytical and Empirical Examination of the Agency Theoretic Approach," Quantitative Marketing and Economics, 3 (1), March 2005, 5-39.

Moorthy, K. Sridhar (1987), "Managing Channel Profits: Comment," Marketing Science, 6(4), Autumn 1987, 375-379.

Nalbantian, Haig R. and Andrew Schotter (1997), "Productivity Under Group Incentives: An Experimental Study," The American Economic Review, 87 (3), June 1997, 314-341.

Narayanan, V.G. and Ananth Raman (2004), "Aligning Incentives in Supply Chains," Harvard Business Review, 82 (11), Nov 2004, 94-102.

Netessine, Serguei and Nils Rudi (2004), "Supply chain structures on the Internet and the role of marketing-operations interaction," Handbook of quantitative supply chain analysis: modeling in the ebusiness era, D. Simchi-Levi, S. D. Wu and M. Shen, Eds., Kluwer.

Netessine, Serguei and Terry A. Taylor (2007), "Product line design and production technology," Marketing Science, 26 (1), Jan/Feb 2007, 101-117.

Porteus, Evan L. and Seungjin Whang (1991), "On Manufacturing/Marketing Incentives," Management Science, 37 (9), Sep 1991, 1166-1181.

Prendergast, Canice (1999), "The Provision of Incentives in Firms," Journal of Economic Literature, 37, March 1999, 7-63.

Prendergast, Canice (2000), "What Trade-Off of Risk and Incentives?," The American Economic Review, 90 (2), May 200, 421-425. 
Raju, Jagmohan S. and V. Srinivasan (1996), "Quota-Based Compensation Plans for Multiterritory Heterogeneous Salesforces," Management Science, 42 (10), Oct 1996, 1454-1462.

Rao, Ram C. (1990), "Compensating Heterogeneous Salesforces: Some Explicit Solutions," Marketing Science, 9 (4), Fall 1990, 319-341.

RetailWire (2007), "Crossing the Marketing and Logistics Divide," http://retailwire.com/Discussions/Sngl_Discussion.cfm/11948.

Sarin, Shikhar and Vijay Mahajan (2001), "The effect of reward structures on the performance of cross-functional product development teams," Journal of Marketing, 65 (2), April 2001, $35-53$.

Shapiro, Benson P. (1977), "Can marketing and manufacturing coexist?" Harvard Business Review, 55 (5), Sep-Oct 1977, 104-114.

Shaw, Douglas G. and Craig Eric Schneier (1995), "Team measurement and rewards: How some companies are getting it right," Human Resource Planning, 18 (3), 1995, 34-49.

Souza, Gilvan C., Barry L. Bayus and Harvey M. Wagner (2004), "New-Product Strategy and Industry Clockspeed," Management Science, 50 (4), April 2004, 537-549.

Stanton, Jeffrey M. (2000), "Reactions to Employee Performance Monitoring: Framework, Review, and Research Directions," Human Performance, 13 (1), 2000, 85-113. 


\section{Appendix}

\section{Proof of Lemma 1}

The firm has to ensure that the expected utilities of the two managers are just equal to their utilities from their outside options. In other words, the constraints in (3) are binding. Hence, the firm sets the salary components of the compensations as $w_{m}=-\alpha_{m} P_{m}+V_{m}(A)$ and $w_{o}=$ $-\alpha_{o} P_{o}+E V_{o}(\chi Q \zeta)$. Folding this into the expression for profit, the firm solves

$$
\max _{\{A, Q\}} E \Pi_{f}^{F B}=r E Y(Q, A)-E C(Q, A)-V_{m}(A)-E V_{o}(\chi Q \zeta)
$$

which, using the substitutions $U=Q-Y, B=D(A)-Y$ and $Y=\min \{Q, D(A)\}$, can be written as

$$
\max _{\{A, Q\}} E \Pi_{f}^{F B}=\left(r+c_{u}+c_{b}\right) E \min \{Q, D(A)\}-\left(c_{o}+c_{u}\right) Q-c_{b} E D(A)-V_{m}(A)-E V_{o}(\chi Q \zeta)
$$

Note that the above is independent of the contract parameters $\alpha_{m}$ and $\alpha_{o}$.

For uniqueness, we need to ensure that the function $E \Pi_{f}^{F B}$ is concave, which is true iff the Hessian matrix is negative semidefinite. The first derivatives are given by

$$
\begin{aligned}
& \frac{\partial E \Pi_{f}^{F B}}{\partial Q}=\left(r+c_{u}+c_{b}\right) \operatorname{Pr}\{D(A)>Q\}-\left(c_{o}+c_{u}\right)-\frac{d E V_{o}(\chi Q \zeta)}{d Q} \\
& \frac{\partial E \Pi_{f}^{F B}}{\partial A}=\left(r+c_{u}+c_{b}\right) \operatorname{Pr}\{D(A)<Q\}-c_{b}-\frac{d V_{m}(A)}{d A}
\end{aligned}
$$

The second derivatives are given by

$$
\begin{aligned}
& \frac{\partial^{2} E \Pi_{f}^{F B}}{\partial Q^{2}}=-\left(r+c_{u}+c_{b}\right) \operatorname{Pr}\{D(A)=Q\}-\frac{d^{2} E V_{o}(\chi Q \zeta)}{d Q^{2}} \\
& \frac{\partial^{2} E \Pi_{f}^{F B}}{\partial A^{2}}=-\left(r+c_{u}+c_{b}\right) \operatorname{Pr}\{D(A)=Q\}-\frac{d^{2} V_{m}(A)}{d A^{2}} \\
& \frac{\partial^{2} E \Pi_{f}^{F B}}{\partial A \partial Q}=\frac{\partial^{2} E \Pi_{f}^{F B}}{\partial Q \partial A}=\left(r+c_{u}+c_{b}\right) \operatorname{Pr}\{D(A)=Q\}
\end{aligned}
$$

Since $V_{o}(\cdot)$ and $V_{m}(\cdot)$ are convex, $\frac{d^{2} E V_{o}(\chi Q \zeta)}{d Q^{2}}>0$ and $\frac{d^{2} V_{m}(A)}{d A^{2}}>0$, which clearly implies that $\frac{\partial^{2} E \Pi_{f}^{F B}}{\partial Q^{2}}<0$ and $\frac{\partial^{2} E \Pi_{f}^{F B}}{\partial A^{2}}<0$ (i.e., both diagonal elements of the Hessian are negative). The 
positivity of the determinant is equal to the following condition:

$$
\frac{\partial^{2} E \Pi_{f}^{F B}}{\partial Q^{2}} \frac{\partial^{2} E \Pi_{f}^{F B}}{\partial A^{2}}-\frac{\partial^{2} E \Pi_{f}^{F B}}{\partial A \partial Q} \frac{\partial^{2} E \Pi_{f}^{F B}}{\partial Q \partial A}>0 .
$$

The left-hand side can be expanded and written as

$$
\left(r+c_{u}+c_{b}\right) \operatorname{Pr}\{D(A)=Q\}\left(\frac{d^{2} E V_{o}(\chi Q \zeta)}{d Q^{2}}+\frac{d^{2} V_{m}(A)}{d A^{2}}\right)+\frac{d^{2} E V_{o}(\chi Q \zeta)}{d Q^{2}} \frac{d^{2} V_{m}(A)}{d A^{2}}
$$

which is clearly positive. Hence, the first-best solution is unique.

\section{Discussion of the Assumption $c_{b} \leq \bar{c}$}

To obtain some intuition into the appropriateness of the assumption $c_{b} \leq \bar{c}$, note that it is violated only when the penalty from backorders is extremely large compared to the marginal cost and the penalty from unsold inventory. To gain simplicity without surrendering any insights, we set $\mu=\sigma$ and $\omega^{2}=1$. Consider the inverse of the above assumption, i.e., $c_{b}>\frac{r\left(2 c_{o}+c_{u}\right)+\left(2 \sigma-c_{o}\right) c_{o}+c_{o}\left(c_{u}+c_{o}\right)}{r+\left(2 \sigma-c_{o}\right)}$. This, to be true, requires $c_{b}$ to be very large as compared to $c_{o}$ and $c_{u}$ for any values of $r$ and $\sigma$. To further see how strong this condition is, note that even if we assume $c_{u}=0$ (i.e., the penalty from unsold inventory is zero), we get the condition $c_{b}>c_{o}\left(\frac{2 r+2 \sigma}{r+2 \sigma-c_{o}}\right)$ which holds only if $c_{b}>c_{o}$ (i.e., the penalty from backorders is higher than the marginal cost of the product), which in itself is a very strong condition. As $c_{u}$ and $c_{b}$ increase, the required value of $c_{b}$ only becomes larger. Hence, our original assumption is reasonable and holds for a typical firm. Anderson, Fitzsimons and Simester (2006) find that the long-run cost of stockouts (in their setting of a mail-order catalog) is lower than both the marginal cost and the penalty from unsold inventory.

\section{Proof of Proposition 1}

Under the assumptions above, the demand distribution takes the form $D(A) \sim$ Uniform $[A+\mu-$ $\sigma, A+\mu+\sigma]$ and the expected effort disutilities are given by $E V_{m}(A)=\frac{1}{2} A^{2}$ and $E V_{o}(Q \zeta)=$ $\frac{1}{2} \operatorname{Var}[\zeta] Q^{2}=\frac{1}{2} \omega^{2} Q^{2}$. Substituting in the first-order conditions $\left.\frac{\partial E \Pi_{f}^{F B}}{\partial Q}\right|_{Q^{F B}}=0$ and $\left.\frac{\partial E \Pi_{f}^{F B}}{\partial A}\right|_{A^{F B}}=$ 0 and solving simultaneously results in the pair $\left(Q^{F B}, A^{F B}\right)$ as shown above. ${ }^{9}$ By Lemma 1 , the solution is unique.

\footnotetext{
${ }^{9}$ Note that our assumptions imply that when there is no sales effort, demand is distributed as Uniform $[\mu-\sigma, \mu+\sigma]$. We assume that the coefficient of variation for this distribution $\frac{\sigma}{\sqrt{3} \mu} \geq \frac{1}{\sqrt{3}}$. This is a very mild assumption, since it will be guaranteed to hold if $\mu$ (mean demand in the absence of sales effort) is small. We need this assumption as a sufficient condition to ensure that $A^{F B}>0$.
} 


\section{Proof of Proposition 2}

According to (1) and (2), in the second stage of the game, given her contract $S_{m}=w_{m}+\alpha_{m} Y$, the marketing manager solves the problem

$$
\begin{aligned}
\max _{A} E \Pi_{m} & =w_{m}+\alpha_{m} E Y-V_{m}(A) \\
\text { or, } \max _{A} E \Pi_{m} & =w_{m}+\alpha_{m} E \min \{Q, D(A)\}-V_{m}(A)
\end{aligned}
$$

and given his contract $S_{o}=w_{o}-\alpha_{o} C$, the operations manager simultaneously solves the problem

$$
\begin{gathered}
\max _{Q} E \Pi_{o}=w_{o}-\alpha_{o} E C-E V_{o}(\chi Q \zeta) \\
\text { or, } \max _{Q} w_{o}+\alpha_{o}\left(c_{u}+c_{b}\right) E \min \{Q, D(A)\}-\alpha_{o}\left(c_{o}+c_{u}\right) Q-\alpha_{o} c_{b} E D(A)-E V_{o}(\chi Q \zeta)
\end{gathered}
$$

The first derivatives are given by

$$
\begin{aligned}
& \frac{d E \Pi_{m}}{d A}=\alpha_{m} \operatorname{Pr}\{D(A)<Q\}-A \\
& \text { and } \frac{d E \Pi_{o}}{d Q}=\alpha_{o}\left(c_{u}+c_{b}\right) \operatorname{Pr}\{D(A)>Q\}-\alpha_{o}\left(c_{o}+c_{u}\right)-\omega^{2} Q .
\end{aligned}
$$

The second derivatives are given by

$$
\begin{aligned}
& \frac{d^{2} E \Pi_{m}}{d A^{2}}=-\left(\alpha_{m} \frac{1}{2 \sigma}+1\right) \\
& \text { and } \frac{d^{2} E \Pi_{o}}{d Q^{2}}=-\left(\alpha_{o}\left(c_{u}+c_{b}\right) \frac{1}{2 \sigma}+\omega^{2}\right) .
\end{aligned}
$$

To obtain unique utility maximizing solutions for both managers, both the second derivatives above should be positive, resulting in the conditions

$$
\begin{aligned}
\alpha_{m}+2 \sigma & >0 \\
\text { and, } \alpha_{o}\left(c_{u}+c_{b}\right)+2 \sigma \omega^{2} & >0 .
\end{aligned}
$$

When these conditions hold, the first-order conditions give the unique solution pair $\left(Q^{*}, A^{*}\right)$ in terms of the contract parameters $\alpha_{m}$ and $\alpha_{o}$

$$
\begin{aligned}
Q^{*} & =\frac{\alpha_{o}\left(\alpha_{m}\left(c_{b}-c_{o}\right)+c_{b}(\mu+\sigma)+c_{u}(\mu-\sigma)-2 c_{o} \sigma\right)}{\alpha_{o}\left(c_{b}+c_{u}\right)+\left(\alpha_{m}+2 \sigma\right) \omega^{2}} \\
A^{*} & =\frac{\alpha_{m}\left(\alpha_{o}\left(c_{b}-c_{o}\right)-(\mu-\sigma) \omega^{2}\right)}{\alpha_{o}\left(c_{b}+c_{u}\right)+\left(\alpha_{m}+2 \sigma\right) \omega^{2}}
\end{aligned}
$$


As in formulation (3), given these values of $A^{*}$ and $Q^{*}$, the firm solves for optimal values of $w_{m}, \alpha_{m}, w_{o}$ and $\alpha_{o}$ to maximize its own profits. First note that the firm simply needs to make the participation constraints in (3) binding. Hence, it sets $w_{m}=-\alpha_{m} E\left[Y \mid Q^{*}, A^{*}\right]+V_{m}\left(A^{*}\right)$ and $w_{o}=\alpha_{o} E\left[C \mid Q^{*}, A^{*}\right]+\omega^{2} V_{o}\left(Q^{*}\right)$. The optimization problem of the firm then becomes (after a little bit of algebra)

$$
\max _{\left\{\alpha_{m}, \alpha_{o}\right\}} E \Pi_{f}=\left(r+c_{u}+c_{b}\right) E \min \left\{Q^{*}, D\left(A^{*}\right)\right\}-\left(c_{o}+c_{u}\right) Q^{*}-c_{b} E D\left(A^{*}\right)-V_{m}\left(A^{*}\right)-\omega^{2} V_{o}\left(Q^{*}\right)
$$

To find the optimal values of $\alpha_{m}$ and $\alpha_{o}$, we can take the first-order conditions w.r.t. both these parameters and solve for them. This, however, gets very unwieldy, so we use a different method to arrive at the optimal values of these parameters. Notice that the expressions for firm profit in (A4) above and in (A1) have the same structure, and will be exactly identical if the firm can achieve $Q^{*} \equiv Q^{F B}$ and $A^{*} \equiv A^{F B}$. Moreover, the first-best solution is unique, which means that if in this case the firm can set contract parameters such that the first-best solution is achieved, $A^{*}$ must be identical to $A^{F B}$ and $Q^{*}$ must be identical to $Q^{F B}$. Therefore, to obtain the optimal contract parameters, we solve for $\alpha_{m}^{*}$ and $\alpha_{o}^{*}$ by equating the solution provided in Proposition 1 and (A3). This gives us the complete characterization of the contracts as the set of parameters $\left\{w_{m}^{*}, \alpha_{m}^{*}, w_{o}^{*}, \alpha_{o}^{*}\right\}$, where

$$
\begin{aligned}
\alpha_{m}^{*} & =\frac{\left(r-c_{o}\right)\left(r+c_{u}+c_{b}\right)-\left(\left(r+c_{u}\right)(\mu-\sigma)+c_{b}(\mu+\sigma)\right) \omega^{2}}{\left(r-c_{o}\right)+c_{b}\left(1+\omega^{2}\right)-(\mu-\sigma) \omega^{2}}, \\
w_{m}^{*} & =-\alpha_{m}^{*} E\left[Y \mid Q^{F B}, A^{F B}\right]+V_{m}\left(A^{F B}\right), \\
\alpha_{o}^{*} & =\frac{\left(\left(r-c_{o}\right)\left(r+c_{u}+c_{b}\right)+\left(r+c_{b}\right)(\mu+\sigma)+c_{u}(\mu-\sigma)-2 c_{o} \sigma\right) \omega^{2}}{-r\left(c_{o}+c_{u}\right)+\left(r\left(c_{b}-c_{o}\right)-c_{o}\left(c_{u}+c_{b}\right)+c_{b}(\mu+\sigma)+c_{u}(\mu-\sigma)-2 c_{o} \sigma\right) \omega^{2}}
\end{aligned}
$$

and $w_{o}^{*}=\alpha_{o}^{*} E\left[C \mid Q^{F B}, A^{F B}\right]+\omega^{2} V_{o}\left(Q^{F B}\right)$,

subject to the conditions $\alpha_{m}^{*}+2 \sigma>0$ and $\alpha_{o}^{*}\left(c_{u}+c_{b}\right)+2 \sigma \omega^{2}>0$.

Using the optimal value for $\alpha_{m}^{*}$, we can write $\alpha_{m}^{*}=\frac{2 \sigma A^{F B}}{Q^{F B}-\left(A^{F B}+\mu-\sigma\right)}$, which is positive, because $A^{F B}+\mu-\sigma \leq Q^{F B} \leq A^{F B}+\mu+\sigma$. Hence, the first condition (for the marketing manager) is always satisfied.

The second condition (for the operations manager; using the optimal value for $\alpha_{o}^{*}$ ), however, is satisfied only if $c_{b}>\frac{c_{o}\left(r+\omega^{2}\left(r+c_{u}+2 \sigma\right)+c_{u}\left(r-\omega^{2}(\mu-\sigma)\right)\right.}{\omega^{2}\left(r-c_{o}+\mu+\sigma\right)}=\bar{c}$, which does not hold by assumption.

Hence, the firm cannot achieve the first-best outcome using contracts of the above form. 


\section{Proofs for Interdependent Contracts}

\section{V.a Proof of Proposition 3}

Given these contracts, the marketing manager solves the same problem as before, and the operations manager solves

$$
\begin{aligned}
& \max _{Q} E \Pi_{o}=w_{o}-\alpha_{o} E C+\beta_{o} E Y-E V_{o}(\chi Q \zeta) \\
& \text { or, } \max _{Q} w_{o}+\left(\alpha_{o}\left(c_{u}+c_{b}\right)+\beta_{o}\right) E \min \{Q, D(A)\}-\alpha_{o}\left(c_{o}+c_{u}\right) Q-\alpha_{o} c_{b} E D(A)-E V_{o}(\chi Q \zeta) .
\end{aligned}
$$

The first derivative is given by

$$
\frac{d E \Pi_{o}}{d Q}=\left(\alpha_{o}\left(c_{u}+c_{b}\right)+\beta_{o}\right) \operatorname{Pr}\{D(A)>Q\}-\alpha_{o}\left(c_{o}+c_{u}\right)-\omega^{2} Q
$$

The second derivative is given by

$$
\frac{d^{2} E \Pi_{o}}{d Q^{2}}=-\left(\left(\alpha_{o}\left(c_{u}+c_{b}\right)+\beta_{o}\right) \frac{1}{2 \sigma}+\omega^{2}\right)
$$

Proceeding exactly as earlier (i.e., solving the first-order conditions for $Q^{*}$ and $A^{*}$ and equating them to $Q^{F B}$ and $A^{F B}$ ) we obtain the coordinating contracts as in the statement of the proposition. The conditions $\alpha_{m}^{*}+2 \sigma>0$ and $\alpha_{o}^{*}\left(c_{u}+c_{b}\right)+\beta_{o}^{*}+2 \sigma \omega^{2}>0$ ensure that the first-order conditions maximize the net utilities of the two managers.

\section{V.b Proof of Corollary 3.1}

We need $\beta_{o, s}^{*}+2 \omega^{2} \sigma>0$. We can write $\beta_{o, s}^{*}=\frac{2 \omega^{2} \sigma Q^{F B}}{\left(A^{F B}+\mu+\sigma\right)-Q^{F B}}$, which is positive, because $A^{F B}+$ $\mu-\sigma \leq Q^{F B} \leq A^{F B}+\mu+\sigma$. Hence, $\beta_{o, s}^{*}+2 \omega^{2} \sigma>0$ holds.

\section{Proofs for Information-Based Contracts}

\section{VI.a Proof of Proposition 4}

Given these contracts, the marketing manager solves the same problem as before, and the operations manager solves

$$
\begin{gathered}
\max _{Q} E \Pi_{o}=w_{o}-\alpha_{u} E U-\alpha_{b} E B-E V_{o}(\chi Q \zeta) \\
\text { or, } \max _{Q} w_{o}+\left(\alpha_{u}+\alpha_{b}\right) E \min \{Q, D(A)\}-\alpha_{u} Q-\alpha_{b} E D(A)-E V_{o}(\chi Q \zeta) .
\end{gathered}
$$


The first derivative is given by

$$
\frac{d E \Pi_{o}}{d Q}=\left(\alpha_{u}+\alpha_{b}\right) \operatorname{Pr}\{D(A)>Q\}-\alpha_{u}-\omega^{2} Q
$$

The second derivative is given by

$$
\frac{d^{2} E \Pi_{o}}{d Q^{2}}=-\left(\left(\alpha_{u}+\alpha_{b}\right) \frac{1}{2 \sigma}+\omega^{2}\right)
$$

Proceeding exactly as we did earlier (i.e., solving the first-order conditions for $Q^{*}$ and $A^{*}$ and equating them to $Q^{F B}$ and $A^{F B}$ ) we obtain the coordinating contracts as in the statement of the proposition. The conditions $\alpha_{m}^{*}+2 \sigma>0$ and $\alpha_{u}^{*}+\alpha_{b}^{*}+2 \sigma \omega^{2}>0$ ensure that the first-order conditions maximize the net utilities of the two managers.

\section{VI.b Proof of Corollary 4.1}

We need $\alpha_{b, s}^{*}+2 \omega^{2} \sigma>0$. We can write $\alpha_{b, s}^{*}=\frac{2 \omega^{2} \sigma Q^{F B}}{\left(A^{F B}+\mu+\sigma\right)-Q^{F B}}$, which is positive, because $A^{F B}+$ $\mu-\sigma \leq Q^{F B} \leq A^{F B}+\mu+\sigma$. Hence, $\beta_{o, s}^{*}+2 \omega^{2} \sigma>0$ holds.

\section{References for Appendix}

Anderson, Eric T., Gavan J. Fitzsimons and Duncan Simester (2006), "Measuring and Mitigating the Costs of Stockouts," Management Science, 52 (11), November 2006, 1751-1763. 


\title{
Supplement to \\ Can We All Get Along? Incentive Contracts to Bridge the Marketing and Operations Divide ${ }^{\dagger}$
}

\author{
Kinshuk Jerath \\ Serguei Netessine \\ Z. John Zhang \\ The Wharton School \\ University of Pennsylvania \\ Jon M. Huntsman Hall \\ 3730 Walnut Street \\ Philadelphia, PA 19104-6340
}

June 2007

\footnotetext{
${ }^{\dagger}$ This supplement is to accompany the paper "Can We All Get Along? Incentive Contracts to Bridge the Marketing and Operations Divide" by Kinshuk Jerath, Serguei Netessine and Z. John Zhang.
} 


\section{Supplement to \\ Can We All Get Along? \\ Incentive Contracts to Bridge the Marketing and Operations Divide}

\section{S.1 Introduction}

When a firm carries more than one product, the distortion in incentives that arises by contracting on total cost with the operations manager discussed in the previous section is present, and can be corrected in the same way. However, we see another distortion, the source of which is that one manager now has to allocate selling or supplying effort among two or more products. This allocation will be suboptimal from the point of view of the firm if incentives are not properly aligned (Baker 2000). In this supplement, we study this distortion and show how it leads a firm to focus more on either its sales arm or its operations arm than to the other. (For the purpose of making this a coherent document, we allow considerable redundancy between the main document and this supplement.)

\section{S.2 Model for Two Products}

We extend our notation used in the one-product case by adding 1 and 2 as subscripts to the symbols to distinguish between the two products. The only change is in the demand system, since the demand for the two products can now be related. We assume that effort exerted to promote one product has an adverse effect on the demand for the other product. We incorporate this by using the following demand system:

$$
D_{i}\left(A_{i}, A_{j}\right)=A_{i}-\theta A_{j}+\mu_{i}+\varepsilon_{i}, j=3-i,
$$

where $0 \leq \theta<1$.

Our analysis for the two-product case proceeds as follows. First, we show that interdependent contracts and information-based contracts can always coordinate the marketing and operations arms of the firm and achieve the first-best outcome. The coordinating contracts, however, are

quite complex, and can be difficult to implement. Compensation schemes observed in reality are much simpler. For practical considerations, we build simplifying assumptions into the incentive contracts, leading to distortions in the managers' incentives due to multitasking, and show that the firm's attempts to mitigate these distortions leads to interesting implications for the choice of organization design.

\section{S.2.1 Coordinating contracts}

Consider the case when every product has its own marketing manager and its own operations manager. We showed in the one-product case that if the firm contracts with the operations manager 
on total inventory cost, it cannot always achieve the first-best outcome. Clearly, this distortion will be seen in the two-product case as well. We also showed for the one-product case that if the firm contracts with the operations manager on sales alone or backorders alone, then it can always achieve coordination. In the two-product case, if the demand for the products is unrelated, it is easy to see that this result will also hold. We now briefly show that even if the demand is interdependent (as in (S.1)) the firm can achieve coordination by using either interdependent contracts or informationbased contracts. Further, contracting with the operations manager only on sales (the simplest interdependent contract) or only on backorders (the simplest information-based contract) can also achieve the first-best outcome for the firm.

Given contracts $S_{m 1}, S_{m 2}, S_{o 1}, S_{o 2}$ the managers solve the following problems simultaneously to obtain $A_{1}^{*}, A_{2}^{*}, Q_{1}^{*}, Q_{2}^{*}$ :

$$
\begin{aligned}
& A_{i}^{*}=\arg \max _{A_{i}} E\left[\Pi_{m i} \mid Q_{i}^{*}, A_{i}, A_{j}^{*}\right]=E\left[S_{m i} \mid Q_{i}^{*}, A_{i}, A_{j}^{*}\right]-V_{m i}\left(A_{i}\right), i=1,2 \\
& Q_{i}^{*}=\arg \max _{Q_{i}} E\left[\Pi_{o i} \mid Q_{i}, A_{i}^{*}, A_{j}^{*}\right]=E\left[S_{o i} \mid Q_{i}, A_{i}^{*}, A_{j}^{*}\right]-E\left[V_{o i}\left(\zeta_{i} Q_{i}\right) \mid Q_{i}\right], i=1,2 .
\end{aligned}
$$

Given these values in terms of the contract parameters, the firm solves for optimal values of the contract parameters to maximize its own profits:

$$
\max \sum_{i=1,2} r_{i} E\left[Y_{i} \mid Q_{i}^{*}, A_{1}^{*}, A_{2}^{*}\right]-E\left[C_{i} \mid Q_{i}^{*}, A_{1}^{*}, A_{2}^{*}\right]-E\left[S_{m i} \mid Q_{i}^{*}, A_{1}^{*}, A_{2}^{*}\right]-E\left[S_{o i} \mid Q_{i}^{*}, A_{1}^{*}, A_{2}^{*}\right]
$$

such that: $\max _{A_{i}} E\left[S_{m i} \mid Q_{i}^{*}, A_{i}, A_{j}^{*}\right]-V_{m i}\left(A_{i}\right), i=1,2$

$$
\max _{Q_{i}} E\left[S_{o i} \mid Q_{i}, A_{i}^{*}, A_{j}^{*}\right]-E\left[V_{o i}\left(\zeta_{i} Q_{i}\right) \mid Q_{i}\right], i=1,2 .
$$

The first-best problem for the firm (when it dictates the actions of the managers) is:

$$
\max _{\left\{A_{1}, A_{2}, Q_{1}, Q_{2}\right\}} \sum_{i=1,2} r_{i} E Y_{i}\left(Q_{i}, A_{1}, A_{2}\right)-E C_{i}\left(Q_{i}, A_{1}, A_{2}\right)-V_{m i}\left(A_{i}\right)-E V_{o i}\left(\zeta_{i} Q_{i}\right)
$$

which can be written as

$$
\begin{aligned}
\max _{\left\{A_{1}, A_{2}, Q_{1}, Q_{2}\right\}} \sum_{i=1,2}[ & \left(r_{i}+c_{u i}+c_{b i}\right) E \min \left\{Q_{i}, D_{i}\left(A_{1}, A_{2}\right)\right\} \\
& \left.-\left(c_{o i}+c_{u i}\right) Q_{i}-c_{b i} E D_{i}\left(A_{1}, A_{2}\right)-V_{m i}\left(A_{i}\right)-E V_{o i}\left(\zeta_{i} Q_{i}\right)\right] .
\end{aligned}
$$

Note that the above is independent of the contract parameters. We assume that the optimal solution to the first-best problem is unique, and denote it by $\left\{A_{1}^{F B}, A_{2}^{F B}, Q_{1}^{F B}, Q_{2}^{F B}\right\}^{10}$.

\footnotetext{
${ }^{10}$ The first-best solution is straightforward to compute using the first-order conditions, but is cumbersome. Except for the effect of the parameter $\theta$, this solution is otherwise similar to the solution of the one-product case. The Hessian determines the conditions under which the first-best solution is unique. See Appendix S.III for the first-best solution in a simplified case.
} 
Now, when the firm does not dictate the actions of the managers, suppose the marketing managers are offered the contracts $S_{m i}=w_{m i}+\alpha_{i} Y_{i}$ and the operations managers are offered the contracts $S_{o i}=w_{o i}-\alpha_{o i} C_{i}+\beta_{o i} Y_{i}$ (i.e., interdependent contracts). We obtain the following proposition.

Proposition S.1 Suppose the firm sells two heterogeneous products with demand specified in (S.1) and interdependent contracts specified above. Then, the firm can always determine contracts to achieve the first-best solution. The simplest interdependent contract that achieves the first-best outcome compensates the operations managers only on the sales for their respective products.

Proof Refer to Appendix S.I.

As in the one-product case, the firm can also achieve coordination using information-based contracts, with the simplest contract compensating the operations managers only on backorders.

We have assumed above that, for each product, the firm employs separate managers for sales and stocking. Suppose now that the managers have to multitask, i.e., one marketing manager manages both products and/or one operations manager manages both products, and the firm uses interdependent contracts or information-based contracts for the operations manager. The firm can still structure the contracts to achieve the first-best outcome, but the coordinating contracts in the most general case are complex, in one of two ways:

- the contracts have a separate variable component for each product, or

- the performance metrics contracted upon are a specific weighted combination of the metrics for each product. (When sales are contracted upon, these weights may not simply be the retail prices, and when backorders are contracted upon, these weights may not simply be the backorder costs for the products.) In other words, contracting on simple aggregate measures like total dollar sales or total backorder costs cannot achieve the first-best outcome.

We provide a mathematical sketch for the above argument in Appendix S.II.

Comparative statics: The comparative statics for the different optimal contract parameters remain the same as in the one-product case with respect to all parameters. However, we have one new parameter $\theta$ denoting the degree to which sales effort for one product hurts the demand for the other product. To focus on the effect of $\theta$, we assume that the two products are identical in every respect. Then, as $\theta$ increases, the first-best levels of sales effort as well as stocking quantity decrease. The optimal reward for sales for the marketing manager decreases with $\theta$ when a separate manager sells each product but increases with $\theta$ when one manager sells both products (otherwise, as $\theta$ increases, he will exert suboptimal effort). For the operations manager, the reward for sales (under the simplest interdependent contract) and the penalty for backorders (under the simplest information-based contract) decrease with increasing $\theta .{ }^{11}$ See Appendix S.III for details.

\footnotetext{
${ }^{11}$ All of these results depend upon the assumption that $(r-\mu)\left(r+c_{u}+c_{b}\right)+\sigma\left(r+c_{u}-c_{b}\right)>0$. Since $\mu$ (mean demand when sales effort is zero) is small and $r>c_{b}$, this assumption holds.
} 


\section{S.2.2 Simple contracts and implications for organization design}

We saw in the previous section that interdependent contracts and information-based contracts can help the firm incentivize the managers to achieve the first-best outcome. The above theoretical result, as we argued, requires one of three conditions to hold:

1. Every product has its own marketing manager and operations manager, so that one manager does only one job (e.g., selling her product or stocking his product).

2. If one manager manages both products (i.e., the sales manager sells both products, or the operations manager stocks both products), her/his compensation plan needs to have a separate variable component for each product.

3. If one manager manages both products and the compensation plan for each manager includes only one variable component, the performance metric contracted upon is a specific weighted function of the sales or cost metrics for the two products, where the weights, in general, differ from retail prices for sales metrics and costs for cost metrics.

In the real world, we usually observe that even when one person manages more than one product, the compensation plan has a single variable component, and the measures contracted upon to determine this variable component are simple measures like total dollar value of sales achieved. This is contrary to conditions two and three above. We restrict ourselves to contracts on sales only for both managers (information-based contracts can achieve the same outcomes, so the choice does not matter). This already removes the distortion due to contracting on total costs discussed earlier. We make the following assumptions:

1. The firm wants to employ as few managers as possible, but not go "too far" from the first-best solution.

2. The firm wants to keep the contracts simple. This means that (1) for every manager there should only be one variable component in the salary, and (2) the performance metric that determines this variable component should be a simple aggregate metric like total dollar sales of the two products.

Under these simple contracts, the firm cannot achieve the first-best outcome in the most general case. One agent makes more than one decision, and from the perspective of the firm, there is an optimal level for each decision. However, under the simple contract offered, the incentives of the managers are misaligned - the effort allocation between the two products that best pays her/him does not best pay the firm. This distortion, tied to the phenomenon of multitasking, is the problem identified in Baker (2000).

What should the firm do to alleviate this problem? Should it always go with one manager for every job? Clearly, we do not see that in the real world and often observe that one employee manages more than one product. What we do see, however, is that firms usually have either a "sales image," i.e., they focus on the sales side and have more employees working as sales managers 
than employees managing operations, or they have a "cost image," i.e., they focus on the costs side and have more employees managing operations. As an example, compare chain-store retailers like Neiman Marcus and Wal-mart. A visit to Wal-mart makes it quite evident that in-store employees are more focused towards managing inventory and less towards providing sales-enhancing customer service. Neiman Marcus, on the other hand, appears to employ several sales managers at its retail outlets who work closely with customers to try to sell more to them. To explain these observations, we propose that the firm can opt for one of the following three forms of organization:

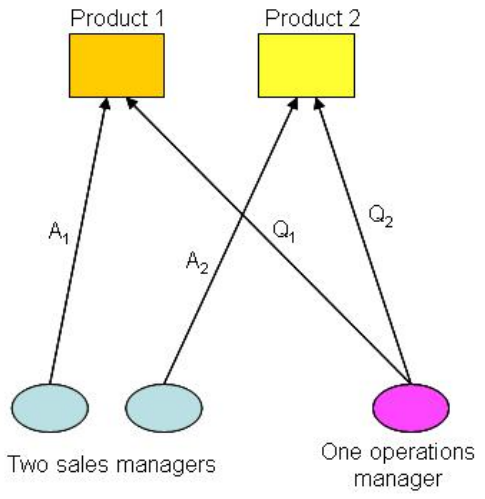

(a) sales-focused design

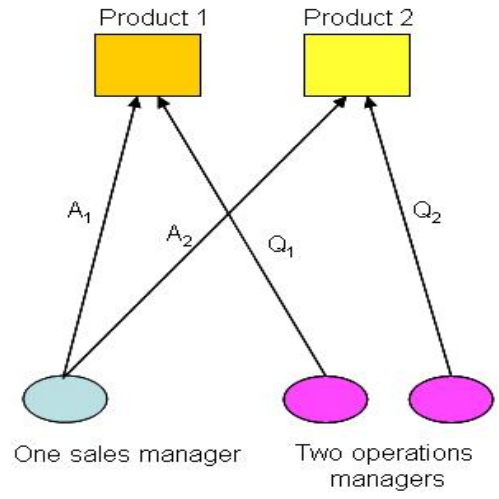

(b) operations-focused design

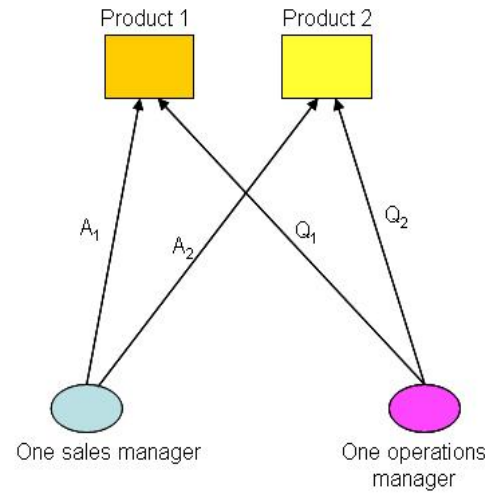

(c) Minimal design

Figure S.1: Schematic representation of the sales-focused, operations-focused and minimal organizations.

1. sales-focused organization: Under this organization scheme, the firm opts for more flexibility on the sales side and has two sales managers (one for each product) and one operations manager. The sales managers decide the sales efforts for their respective products and are rewarded on the dollar sales achieved for their respective products. The operations manager jointly decides the quantity stocked for each product and is rewarded on the total dollar sales achieved for the two products. Figure 1(a) shows a schematic representation of this design. Formally, the firm offers each marketing manager the contract $S_{m i}=w_{m i}+\alpha_{m i} r_{i} Y_{i}$ and the operations manager the contract $S_{o}=w_{o}+\beta_{o}\left(r_{1} Y_{1}+r_{2} Y_{2}\right)$. In the backward induction solution of the associated game, the three managers, given their contracts, simultaneously determine the four quantities $A_{1}^{*}, A_{2}^{*}, Q_{1}^{*}, Q_{2}^{*}$ by maximizing their utilities. Given these quantities, the firm determines the parameters $w_{m 1}, w_{m 2}, \alpha_{m 1}, \alpha_{m 2}, w_{o}$ and $\beta_{o}$.

2. operations-focused organization: Under this organization scheme, the firm opts for more flexibility on the operations side and has two operations managers (one for each product) and one sales manager. The operations managers decide the stocking levels for their respective products and are rewarded on the dollar sales achieved for their respective products. The sales manager jointly decides the sales effort for each product and is rewarded on the total dollar sales achieved for the two products. Figure 1(b) shows a schematic representation of this design. Formally, the firm offers the sales manager the contract $S_{m}=w_{m}+\alpha_{m}\left(r_{1} Y_{1}+r_{1} Y_{2}\right)$ 
and the operations managers the contracts $S_{o i}=w_{o i}+\beta_{o i} r_{i} Y_{i}$. The associated game proceeds in the same manner as above.

3. Minimal organization: Under this organization scheme, the firm has one sales manager and one operations manager. The sales manager jointly decides the sales effort for each product and is rewarded on the total dollar sales achieved for the two products. The operations manager jointly decides the quantity stocked for each product and is rewarded on the total dollar sales achieved for the two products. Figure 1(c) shows a schematic representation of this design. Formally, the firm offers the sales manager the contract $S_{m}=w_{m}+\alpha_{m}\left(r_{1} Y_{1}+r_{2} Y_{2}\right)$ and the operations manager the contract $S_{o}=w_{o}+\beta_{o}\left(r_{1} Y_{1}+r_{2} Y_{2}\right)$. The associated game proceeds in the same manner as above.

Under a sales-focused design, the sales levels are close to first-best, but both stocking quantities are distorted away from first-best - one product is stocked higher than the optimal level and the other is stocked lower than the optimal level. Under an operations-focused design, the sales are distorted in a similar way, but the stocking levels are close to optimal. Based on the product and demand characteristics for the two products, distortions in either the sales arm or the operations arm will be more harmful for the firm, so it will prefer one of these two organizational structures. The firm's choice is to finely control one side but to settle for a distortion on the other to limit the size of the salesforce. The point of interest here is how close the firm can get to the fully coordinated outcome using one of these structures. Following the intuition above, we provide below some broad results regarding when it will choose which design and why. The analytical solutions to the games outlined above are intractable so we resort to a numerical maximization procedure to determine the optimal contract parameters and associated actions for the managers.

Numerical analysis: For the numerical analysis, note that the major components of the firm's net profits are the revenues from sales and the salaries of the managers to compensate them for their efforts. We assume marginal costs to be zero so that the retail prices effectively act as margins. The inventory cost due to the mismatch between demand and quantity stocked is much smaller. This is due to two reasons: (1) this component is determined by the expected difference between quantity stocked and demand (both for unsold inventory and backorders) and these differences are small compared to expected sales, and (2) per-unit costs are lower than per-unit retail prices.

We vary the parameters in the following manner to generate wide asymmetry between the two products: (1) $\theta \in\{0,0.1,0.2,0.3\},(2) r_{1}=8, r_{2} \in\{5,6,7,8,9,10,11\}$, (3) $\sigma_{1}=2, \sigma_{2} \in$ $\{1,1.5,2,2.5,3\}$, and (4) $\omega_{1}^{2}=1, \omega_{2}^{2} \in\{0.5,0.75,1,1.25,1.5\}$. The values for the other parameters are $c_{u 1}=c_{u 2}=4, c_{b 1}=c_{b 2}=4$ and $\mu_{1}=\mu_{2}=0.1$. The parameter values are chosen to parallel the numerical analysis presented in Netessine and Rudi (2004) who have a similar model.

The most important result from our numerical analysis is that the choice of organization design can have a major influence on the profits of the firm. Hence, it is important for a firm to correctly decide its "organization focus." 
Result 1: Under certain scenarios, the firm has a clear preference for one kind of organization design over the other.

There are several scenarios that we identify where, between sales-focused and operations-focused design, the better choice can lead to a profit that is very close to the first-best profit (99\% of first-best) but the wrong design choice can lead to immensely lower profits (over $50 \%$ lower than first-best). This is because, as mentioned earlier, a sales-focused design distorts the decisions on the operations side while an operations-focused design distorts the decisions on the sales side, and one kind of distortion can lead to a more severe impact than the other. For instance, when $\theta=0.2, r_{1}=8, r_{2}=6, \sigma_{1}=2, \sigma_{2}=3, \omega_{1}^{2}=\omega_{2}^{2}=1$, sales-focused design can achieve a profit of $99 \%$ of the first-best profit, while operations-focused design achieves a profit of only $40 \%$ of the first-best profit.

Result 2: For the parameter values considered above, the firm can get very close to the first-best outcome when it has the choice of sales-focused or operations-focused design. However, when the firm is restricted to a minimal design, the profit is much further away from the first-best profit.

Always choosing a minimal design can take the firm very far from the first-best profit (mean deviation 22.0\%). Always choosing sales-focused or always choosing operations-focused design can lead to a substantial difference from first-best (overall mean deviation 4.5\%). However, choosing the better of sales-focused or operations-focused design for each scenario gives a mean deviation of only $0.8 \%$. This suggests that most firms will opt for one of sales-focused design or operationsfocused design and supports the observation pointed out earlier that almost all firms have either a "sales image" or a "cost image." Broadly speaking, when retail prices are low the firm prefers an operations-focused design, because the firm needs to "get it right" on the costs side. If the design is operations-focused, the firm settles for suboptimal sales but can set the stocking quantities such that overall costs are lower. If the design is sales-focused, the firm takes a hit on costs. Since retail prices are low, not a lot is lost in revenue while the benefit from cost reduction is more significant.

The above results provide some insight into how the underlying objective of aligning marketing and operations, while keeping the size of the salesforce small and compensation contracts simple, can influence the organization of a firm. The purpose of this section was to show the existence of these effects rooted in distortions in incentive structures due to multitasking; characterizing the exact conditions governing the preference of one design over another requires a more detailed study which we propose as a direction for future research.

\section{References}

Baker, George (2000), "The Use of Performance Measures in Incentive Contracting," The American Economic Review, 90 (2), May 2000, 415-420. 
Netessine, Serguei and Nils Rudi (2004), "Supply chain structures on the Internet and the role of marketing-operations interaction," Handbook of quantitative supply chain analysis: modeling in the ebusiness era, D. Simchi-Levi, S. D. Wu and M. Shen, Eds., Kluwer. 


\section{Appendix to Supplement}

\section{S.I Proof of Proposition S.1}

Let $A_{1}^{F B}, A_{2}^{F B}, Q_{1}^{F B}, Q_{2}^{F B}$ denote the first-best solution.

Given the contracts $S_{m i}=w_{m i}+\alpha_{i} Y_{i}$ and $S_{o i}=w_{o i}-\alpha_{o i} C_{i}+\beta_{o i} Y_{i}$, the first derivatives for the managers' net utility functions are

$$
\begin{array}{crl}
\frac{d E \Pi_{m i}}{d A_{i}} & =\alpha_{m i} \operatorname{Pr}\left\{D_{i}>Q_{i}\right\}-A_{i}, & i=\{1,2\} \\
\text { and } \frac{d E \Pi_{o i}}{d Q_{i}}=\left(\alpha_{o i}\left(c_{u i}+c_{b i}\right)+\beta_{o i}\right) \operatorname{Pr}\left\{D_{i}>Q_{i}\right\}-\alpha_{o i}\left(c_{o i}+c_{u i}\right)-\omega_{i}^{2} Q_{i}, & i=\{1,2\}
\end{array}
$$

The second derivatives are

$$
\begin{aligned}
\frac{d^{2} E \Pi_{m i}}{d A_{i}^{2}} & =-\left(\alpha_{m i} \frac{1}{2 \sigma_{i}}+A_{i}\right), & i=\{1,2\} \\
\text { and } \frac{d^{2} E \Pi_{o i}}{d Q_{i}^{2}} & =-\left(\left(\alpha_{o i}\left(c_{u i}+c_{b i}\right)+\beta_{o i}\right) \frac{1}{2 \sigma_{i}}+\omega_{i}^{2}\right), & i=\{1,2\} .
\end{aligned}
$$

Solving the first-order conditions for the optimal quantities and sales efforts and equating them to the first-best levels, we obtain the following specification for the contract parameters:

$$
\begin{aligned}
\alpha_{m i} & =\frac{2 A_{i}^{F B} \sigma_{i}}{Q_{i}^{F B}-\left(A_{i}^{F B}-\theta A_{j}^{F B}+\mu_{i}-\sigma_{i}\right)} \\
\alpha_{o i} & +\frac{\left(A_{i}^{F B}-\theta A_{j}^{F B}+\mu_{i}+\sigma_{i}\right)-Q_{i}^{F B}}{\left(c_{b i}+c_{u i}\right)\left(\left(A_{i}^{F B}-\theta A_{j}^{F B}+\mu_{i}+\sigma_{i}\right)-Q_{i}^{F B}\right)-2 \sigma_{1}\left(c_{o i}+c_{u i}\right)} \beta_{o i} \\
& =\frac{2 \omega_{i}^{2} \sigma_{i} Q_{i}^{F B}}{\left(c_{b i}+c_{u i}\right)\left(\left(A_{i}^{F B}-\theta A_{j}^{F B}+\mu_{i}+\sigma_{i}\right)-Q_{i}^{F B}\right)-2 \sigma_{1}\left(c_{o i}+c_{u i}\right)}, i=\{1,2\}, j=2-i .
\end{aligned}
$$

The simplest interdependent contract for the operations manager is given by

$$
\begin{aligned}
& \alpha_{o i, s}=0 \\
& \beta_{o i, s}=\frac{2 \omega_{i}^{2} \sigma_{i} Q_{i}^{F B}}{\left(A_{i}^{F B}-\theta A_{j}^{F B}+\mu_{i}+\sigma_{i}\right)-Q_{i}^{F B}}
\end{aligned}
$$

which can always coordinate, since $A_{i}^{F B}-\theta A_{j}^{F B}+\mu_{i}-\sigma_{i} \leq Q_{i}^{F B} \leq A_{i}^{F B}-\theta A_{j}^{F B}+\mu_{i}+\sigma_{i}$.

\section{S.II Coordinating Contracts When Managers Multitask}

We consider the case of interdependent contracts. The argument for information-based contracts proceeds along similar lines. When a single marketing manager sells both products and a single 
operations manager supplies both products, the firm offers them the contracts $S_{m}=w_{m}+\alpha_{m 1} Y_{1}+$ $\alpha_{m 2} Y_{2}$ and $S_{o}=w_{o}-\alpha_{o 1} C_{1}+\beta_{o 1} Y_{1}-\alpha_{o 2} C_{2}+\beta_{o 2} Y_{2}$ respectively. The first derivatives for the managers' utility functions are given by

$$
\begin{array}{cr}
\frac{\partial E \Pi_{m}}{\partial A_{i}}=\alpha_{m i} \operatorname{Pr}\left\{D_{i}>Q_{i}\right\}-A_{i}-\theta \alpha_{m j} \operatorname{Pr}\left\{D_{j}>Q_{j}\right\}, & i=\{1,2\}, j=2-i \\
\text { and } \frac{\partial E \Pi_{o}}{\partial Q_{i}}=\left(\alpha_{o i}\left(c_{u i}+c_{b i}\right)+\beta_{o i}\right) \operatorname{Pr}\left\{D_{i}>Q_{i}\right\}-\alpha_{o i}\left(c_{o i}+c_{u i}\right)-k_{o i} Q_{i}, & i=\{1,2\} .
\end{array}
$$

Solving the first-order conditions for the optimal quantities and sales efforts and equating them to the first-best levels, we obtain the following specification for the contract parameters:

$$
\begin{aligned}
\alpha_{m i} & =\frac{2\left(A_{i}^{F B}+\theta A_{j}^{F B}\right) \sigma_{i}}{\left(1-\theta^{2}\right)\left(Q_{i}^{F B}-\left(A_{i}^{F B}-\theta A_{j}^{F B}+\mu_{i}-\sigma_{i}\right)\right)} \\
\text { and } \alpha_{o i} & +\frac{\left(A_{i}^{F B}-\theta A_{j}^{F B}+\mu_{i}+\sigma_{i}\right)-Q_{i}^{F B}}{\left(c_{b i}+c_{u i}\right)\left(\left(A_{i}^{F B}-\theta A_{j}^{F B}+\mu_{i}+\sigma_{i}\right)-Q_{i}^{F B}\right)-2 \sigma_{1}\left(c_{o i}+c_{u i}\right)} \beta_{o i} \\
& =\frac{2 k_{o i} \sigma_{i} Q_{i}^{F B}}{\left(c_{b i}+c_{u i}\right)\left(\left(A_{i}^{F B}-\theta A_{j}^{F B}+\mu_{i}+\sigma_{i}\right)-Q_{i}^{F B}\right)-2 \sigma_{1}\left(c_{o i}+c_{u i}\right)}, i=\{1,2\}, j=2-i .
\end{aligned}
$$

The simplest interdependent contract for the operations manager is given by

$$
\begin{aligned}
\alpha_{o i, s} & =0 \\
\text { and } \beta_{o i, s} & =\frac{2 k_{o i} \sigma_{i} Q_{i}^{F B}}{\left(A_{i}^{F B}-\theta A_{j}^{F B}+\mu_{i}+\sigma_{i}\right)-Q_{i}^{F B}}
\end{aligned}
$$

which can always coordinate, since $A_{i}^{F B}-\theta A_{j}^{F B}+\mu_{i}-\sigma_{i} \leq Q_{i}^{F B} \leq A_{i}^{F B}-\theta A_{j}^{F B}+\mu_{i}+\sigma_{i}$.

The contracts above assume a separate piece-rate reward (i.e., a separate variable component) for each product for both managers. If the performance metric of the marketing manager is defined as $P_{m}=\sum_{i=1,2} \lambda_{m i} Y_{i}$, where $\lambda_{m i}=\alpha_{m i}$ above, and the performance metric of the operations manager is defined as $P_{o}=\sum_{i=1,2} \lambda_{o i} Y_{i}$, where $\lambda_{o i}=\beta_{o i, s}$ above, then the contracts $S_{m}=w_{m}+P_{m}$ and $S_{o}=w_{o}+P_{o}$ achieve coordination. However, since $\lambda_{\cdot i} \neq r_{i}$ in general, these metrics differ from aggregate dollar sales.

\section{S.III Effect of $\theta$}

The solution for the case of two products is similar to the solution for the one-product case, but is cumbersome to write. The main difference is the effect of the parameter $\theta$, which measures the extent to which the sales effort for one product hurts the demand for the other product. To focus on how $\theta$ influences the solution, we provide the expressions for the first-best sales efforts and stocking levels under the assumption that the two products are identical in all respects, but sales effort for one product has a negative impact on the demand for the other product (as in (4)).

Using the notation $Q^{2 F B}=Q_{1}^{F B}=Q_{2}^{F B}$ and $A^{2 F B}=A_{1}^{F B}=A_{2}^{F B}$, the first-best solution is 
given by the following expressions:

$$
\begin{aligned}
Q^{2 F B} & =\frac{(1-\theta)^{2}\left(r-c_{o}\right)\left(r+c_{u}+c_{b}\right)+\left(r+c_{b}\right)(\mu+\sigma)+c_{u}(\mu-\sigma)-2 \sigma c_{o}}{\left(r+c_{u}+c_{b}\right)\left(1+\omega^{2}(1-\theta)^{2}\right)+2 \sigma \omega^{2}} \\
\text { and } A^{2 F B} & =\frac{(1-\theta)\left(\left(r-c_{o}\right)\left(r+c_{u}+c_{b}\right)-\left(\left(r+c_{u}\right)(\mu-\sigma)+c_{b}(\mu+\sigma)\right) \omega^{2}\right)}{\left(r+c_{u}+c_{b}\right)\left(1+\omega^{2}(1-\theta)^{2}\right)+2 \sigma \omega^{2}} .
\end{aligned}
$$

Using the above, we can characterize the parameters of the coordinating contracts. The optimal piece-rate rewards for sales for the marketing managers when one manager manages a single product are given by (refer to Appendix S.I)

$$
\alpha_{m}=\frac{2 A^{2 F B} \sigma}{Q^{2 F B}-\left((1-\theta) A^{2 F B}+\mu-\sigma\right)} .
$$

The optimal piece-rate rewards for sales for the marketing managers when one manager manages both products are given by (refer to Appendix S.II)

$$
\alpha_{m}=\frac{2 A^{2 F B} \sigma}{(1-\theta)\left(Q^{2 F B}-\left((1-\theta) A^{2 F B}+\mu-\sigma\right)\right)} .
$$

Under the simplest interdependent contract, the piece-rate rewards for sales for the operations manager(s) are (refer to Appendices S.I and S.II)

$$
\beta_{o}=\frac{2 \omega^{2} \sigma Q^{2 F B}}{\left((1-\theta) A^{2 F B}+\mu+\sigma\right)-Q^{2 F B}} .
$$

To obtain the comparative statics for the above parameters w.r.t. $\theta$, we can simply take the derivatives w.r.t. $\theta$. 